\title{
Social Perspective Taking
}

\section{Citation}

Roan, Linda, Beret Strong, Paulette Foss, Mark Yager, Hunter Gehlbach, and Kimberly A. Metcalf. September 2009. Social Perspective Taking (Technical Report 1259). Arlington, VA: U.S. Army Research Institute for the Behavioral and Social Sciences.

\section{Permanent link}

http://nrs.harvard.edu/urn-3:HUL.InstRepos:4556387

\section{Terms of Use}

This article was downloaded from Harvard University's DASH repository, and is made available under the terms and conditions applicable to Other Posted Material, as set forth at http:// nrs.harvard.edu/urn-3:HUL.InstRepos:dash.current.terms-of-use\#LAA

\section{Share Your Story}

The Harvard community has made this article openly available.

Please share how this access benefits you. Submit a story.

\section{Accessibility}




\title{
Technical Report 1259
}

\section{Social Perspective Taking}

\section{Linda Roan, Beret Strong, Paulette Foss, Mark Yager eCrossCulture Corporation}

\author{
Hunter Gehlbach \\ Harvard Graduate School of Education \\ Kimberly A. Metcalf \\ U.S. Army Research Institute
}

September 2009

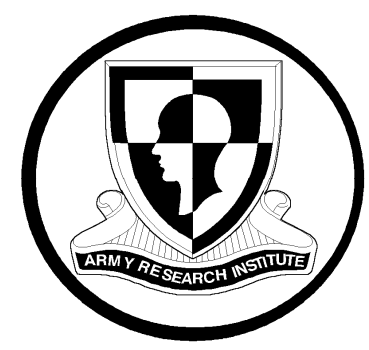

United States Army Research Institute for the Behavioral and Social Sciences 


\section{U.S. Army Research Institute for the Behavioral and Social Sciences}

\section{A Directorate of the Department of the Army Deputy Chief of Staff, G1}

Authorized and approved for distribution:

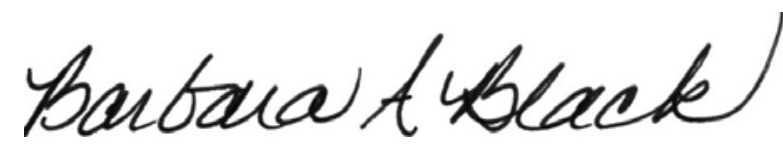

BARBARA A. BLACK, Ph.D. Research Program Manager Training and Leader Development Division

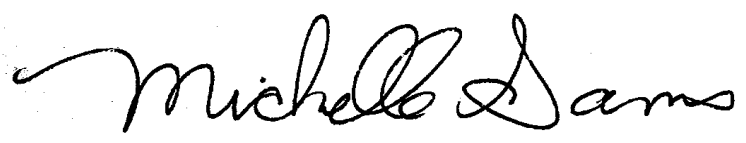

MICHELLE SAMS, Ph.D. Director

Technical review by

Dr. Allison Abbe, U.S. Army Research Institute

Dr. Gregory A. Ruark, U.S. Army Research Institute

\section{NOTICES}

DISTRIBUTION: Primary distribution of this Technical Report has been made by ARI. Please address correspondence concerning distribution of reports to: U.S. Army Research Institute for the Behavioral and Social Sciences, Attn: DAPE-ARI-ZXM, 2511 Jefferson Davis Highway, Arlington, Virginia 22202-3926.

FINAL DISPOSITION: This Technical Report may be destroyed when it is no longer needed. Please do not return it to the U.S. Army Research Institute for the Behavioral and Social Sciences.

NOTE: The findings in this Technical Report are not to be construed as an official Department of the Army position, unless so designated by other authorized documents. 


\section{REPORT DOCUMENTATION PAGE}

\begin{tabular}{|c|c|c|}
\hline $\begin{array}{l}\text { 1. REPORT DATE (dd-mm-yy) } \\
\text { October } 2009\end{array}$ & $\begin{array}{l}\text { 2. REPORT TYPE } \\
\text { Final }\end{array}$ & $\begin{array}{l}\text { 3. DATES COVERED (from. .. to) } \\
\text { May } 2007 \text { - November } 2007\end{array}$ \\
\hline \multicolumn{2}{|l|}{$\begin{array}{l}\text { 4. TITLE AND SUBTITLE } \\
\text { Social Perspective Taking }\end{array}$} & $\begin{array}{l}\text { 5a. CONTRACT OR GRANT NUMBER } \\
\text { W91WAW-07-P-0286 }\end{array}$ \\
\hline & & $\begin{array}{l}\text { 5b. PROGRAM ELEMENT NUMBER } \\
622785\end{array}$ \\
\hline \multirow{3}{*}{\multicolumn{2}{|c|}{$\begin{array}{l}\text { 6. AUTHOR(S) } \\
\text { Linda Roan, Beret Strong, Paulette Foss and Mark Yager } \\
\text { (eCrossCulture Corporation); Hunter Gehlbach (Harvard Graduate } \\
\text { School of Education); Kimberly A. Metcalf (U.S. Army Research } \\
\text { Institute for the Behavioral and Social Sciences) }\end{array}$}} & $\begin{array}{l}\text { 5c. PROJECT NUMBER } \\
\text { A790 }\end{array}$ \\
\hline & & $\begin{array}{l}\text { 5d. TASK NUMBER } \\
333\end{array}$ \\
\hline & & 5e. WORK UNIT NUMBER \\
\hline \multicolumn{2}{|c|}{$\begin{array}{ll}\text { 7. PERFORMING ORGANIZATION NAME(S) AND ADDRESS(ES) } \\
\text { eCrossCulture Corporation } & \text { Harvard Grad. School of Education } \\
77729^{\text {th }} \text { Street, Suite } 202 & \text { Appian Way, Cambridge, MA } \\
\text { Boulder, CO } 80303 & 02138\end{array}$} & $\begin{array}{l}\text { 8. PERFORMING ORGANIZATION REPORT } \\
\text { NUMBER }\end{array}$ \\
\hline \multirow{2}{*}{\multicolumn{2}{|c|}{$\begin{array}{l}\text { 9. SPONSORING/MONITORING AGENCY NAME(S) AND ADDRESS(ES) } \\
\text { U.S. Army Research Institute for the Behavioral and Social Sciences } \\
\text { ATTN: DAPE-ARI-RK } \\
851 \text { McClellan Avenue } \\
\text { Fort Leavenworth, KS } 66027-1360\end{array}$}} & $\begin{array}{l}\text { 10. MONITOR ACRONYM } \\
\text { ARI-FLRU }\end{array}$ \\
\hline & & $\begin{array}{l}\text { 11. MONITOR REPORT NUMBER } \\
\text { Technical Report } 1259\end{array}$ \\
\hline
\end{tabular}

12. DISTRIBUTION/AVAILABILITY STATEMENT

Approved for public release; distribution is unlimited.

13. SUPPLEMENTARY NOTES

Contracting Officer's Representative and Subject Matter POC: Dr. Kimberly Metcalf

14. ABSTRACT (Maximum 200 words): The current mindset of the Army is that it must be able to win our Nation's wars while at the same time ready to assist in stability operations (U.S. Department of the Army, 2008). A challenge is that Soldiers often have to bridge large cultural gaps and may lack the language skills to effectively engage with the host of individuals now present in these operations including the local populace, host nation security forces, coalition partners and other foreign governmental and nongovernmental agencies. Perspective taking - described more formally as "Social Perspective Taking" (SPT) - is an interpersonal technique which may address these challenges. SPT is a skill often learned throughout life but may be very difficult in cross-cultural interactions. This report describes the results of a literature review and SME and Soldier interviews regarding the knowledge, skills, and abilities (KSAs) needed to develop SPT and the methods used to train SPT. Based on this information a four module curriculum is proposed which utilizes a four-step method for the development of SPT. The curriculum trains Soldiers how to accurately consider the host-national's perspective without cultural bias and erroneous assumptions and allows Soldiers to meet host-national goals while accomplishing U.S. missions and objectives.

15. SUBJECT TERMS

Social perspective taking, cultural training, cross-cultural skills, cultural understanding

\begin{tabular}{|c|c|c|c|c|c|}
\hline \multicolumn{3}{|c|}{ SECURITY CLASSIFICATION OF } & \multirow{2}{*}{$\begin{array}{l}\text { 19. LIMITATION OF } \\
\text { ABSTRACT } \\
\text { Unlimited }\end{array}$} & \multirow{2}{*}{$\begin{array}{l}\text { 20. NUMBER } \\
\text { OF PAGES } \\
\quad 64\end{array}$} & \multirow{2}{*}{$\begin{array}{l}\text { 21. RESPONSIBLE PERSON } \\
\text { Ellen Kinzer } \\
\text { Technical Publications Specialist } \\
\text { 703-602-8049 }\end{array}$} \\
\hline $\begin{array}{l}\text { 16. REPORT } \\
\text { Unclassified }\end{array}$ & $\begin{array}{l}\text { 17. ABSTRACT } \\
\text { Unclassified }\end{array}$ & $\begin{array}{l}\text { 18. THIS PAGE } \\
\text { Unclassified }\end{array}$ & & & \\
\hline
\end{tabular}


Technical Report 1259

\title{
Social Perspective Taking
}

\author{
Linda Roan, Beret Strong, Paulette Foss and Mark Yager \\ eCrossCulture Corporation \\ Hunter Gehlbach \\ Harvard Graduate School of Education \\ Kimberly A. Metcalf \\ U.S. Army Research Institute
}
Fort Leavenworth Research Unit
Stanley M. Halpin, Chief

U.S. Army Research Institute for the Behavioral and Social Sciences 2511 Jefferson Davis Highway, Arlington, Virginia 22202-3926

October 2009 


\section{SOCIAL PERSPECTIVE TAKING}

\section{EXECUTIVE SUMMARY}

Research Requirement:

The current mindset of the Army is that it must be trained and able to win our Nation's wars while at the same time ready to assist in stability operations (U.S. Department of the Army, 2008). There is also recognition that "in any conflict, the population in the area of operations will be a key factor...” (U.S. Department of the Army, 2008, p. 1-4). A challenge is that U.S. Soldiers often have to bridge large cultural gaps and may lack the language skills to effectively engage with the host of individuals now present in the battlefield including the local populace, host nation security forces, coalition partners and other foreign governmental and nongovernmental agencies. Perspective taking described more formally as "Social Perspective Taking" (SPT) is an interpersonal technique which can be used to address these challenges. Although SPT is a skill often learned throughout life, it can be very difficult in cross-cultural interactions. For example, consider that many Soldiers have had no cross-cultural experience prior to deployment yet need to deal with complex issues related to tribalism, resource rights, and shifting alliances in-theatre (Masellis, 2009). Performed correctly, SPT allows the Soldier to accurately consider the host-national's perspective without cultural bias and erroneous assumptions. The goal of this research was to develop a curriculum to improve Soldiers' social perspective taking thereby allowing Soldiers to understand host-national goals while accomplishing U.S. missions and objectives.

Procedure:

The research emphasis of this effort focused on identifying an initial set of knowledge, skills (KSAs) useful in SPT and an analysis of various military missions where their successful application could provide Soldiers with maximum benefits in terms of safety, communication, and mission success. An extensive literature review was conducted and six prominent academic experts in the SPT domain as well as four Soldiers provided importance ratings for each of the KSAs determined through the literature review. Four of the SPT academic SMEs and eight Soldiers (four of whom also completed the survey) also participated in follow-up iterative interviews. The interviews were conducted to assess their perceptions of the need for and utility of SPT knowledge, skills and training; the Soldiers provided further information regarding their use of SPT while deployed in Iraq and Afghanistan. The survey and interview findings aided the winnowing of an initial set of 41 SPT skills to a list of 22. The report details a four step method for teaching these SPT skills.

Findings:

The report includes a discussion of a broad literature review related to SPT, survey and interview results with SPT academic SMEs and Soldiers, and a review of 
methodologies used for training perspective taking. These efforts led to the following conclusions: (1) the KSAs most helpful for Soldiers to improve their SPT skills included communication skills, hypothesizing skills, and an awareness of key perceptual biases that lead to incorrect assumptions about the motivations, thoughts, feelings, and behaviors of others, (2) the best strategies for verifying one's hypothesis about the thoughts and feelings of a person from another culture involve communication, (3) because most people have a bias in favor of believing that their first hypothesis is likely to be the correct one, it is also important to go beyond that first guess about the perspective of the other person to consider other options, and then (4) to use interpersonal communication to check accuracy.

In light of these conclusions a four module curriculum is described which is based on engaging in a four step method of perspective taking. The four step method described has been adapted from SPT theory and applied to settings involving Soldiers. The fourstep method will enable Soldiers to gather relevant information, hypothesize about possible perspectives, check in with the other person for more information and confirming or disconfirming evidence, and apply the information gleaned about the other's perspective to the goals of the mission at hand. With sufficient practice, the Soldier can achieve automaticity with the four-step method by learning to avoid common perceptual biases (e.g., fundamental attribution error), to create more than one hypothesis about the other person's perspective, and make a habit of checking in whenever possible to see if any of the hypotheses are correct. The proposed curriculum is designed to effectively improve SPT KSAs in interpersonal contexts globally whether or not the Soldier has received culture training to increase country-specific cultural knowledge.

Utilization and Dissemination of Findings:

The information summarized in this report suggests that SPT training can be a significant benefit to Soldiers in cross-cultural environments. Further, intercultural SPT can be taught in cultural general contexts without orientation towards a specific country. 


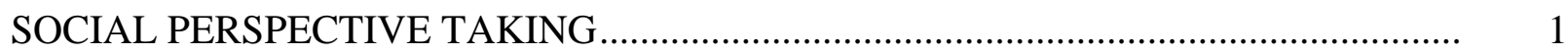

LITERATURE REVIEW ………….........................................................................

Definition of Social Perspective Taking .................................................................... 2

Benefits of Social Perspective Taking ....................................................................... 3

Potential Drawbacks of Social Perspective Taking ................................................ 3

The Social Perspective Taking Process ………………............................................

Understanding the Self................................................................................ 4

Self through the lens of personal experience ...................................... 4

Self through the lens of the American cultural perspective............... 5

Taking the Perspective of Someone Similar to Ourselves............................................ 6

Perspective Taking Theories......................................................................... 6

Perspective Taking as a Two Stage Process .................................................. 7

Interpersonal Communication............................................................ 8

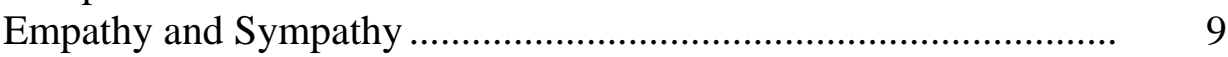

Taking the Perspective of a Culturally Different Other ............................................. 10

Ethnocentrism ...................................................................................... 10

Respect for and Valuing of Others.............................................................. 11

Emotional Regulation .................................................................................. 11

Reliance on Cultural Knowledge Alone ...................................................... 12

In-group/Out-group Bias............................................................................ 13

Cross-Cultural Communication .................................................................... 14

SURVEYS AND INTERVIEWS TO VET KSAs FROM ACADEMIC LITERATURE ... 15 SPT Academic SME Surveys and Interviews....................................................... 15

Soldier Surveys and Interviews ............................................................................. 16

TEACHING METHODOLOGIES FOR SPT ………………………………….............. 19

Videotape ............................................................................................. 19

Case Studies ........................................................................................... 19

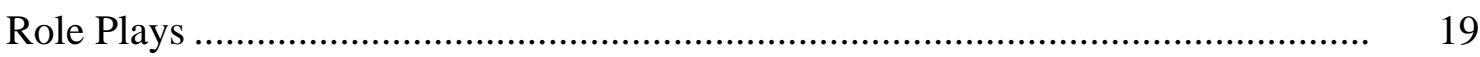

Branching Exercises........................................................................................ 20

Pair Share of Small Group Discussion and Exercises ............................................... 20

A PROPOSED CIRRICULUM FOR SOLDIERS TO LEARN SPT SKILLS .................... 20

Propensity: Motivating the Soldier to Learn SPT .................................................... 21

The Four Step Method ......................................................................................... 22

Step 1: You don’t know what you don’t know ............................................... 22 
CONTENTS (continued)

Page

Step 2: Consider self, then other ............................................................ 22

Step 3: Check in .................................................................................... 23

Step 4: Invest in outcome .................................................................. 23

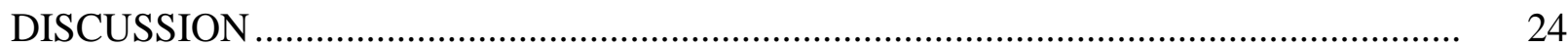

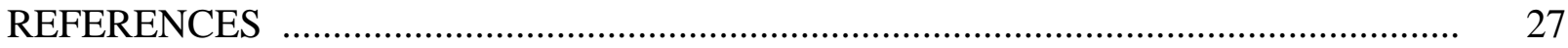

APPENDIX A: FULL SET OF 41 PERSPECTIVE TAKING KSAs: ORGANIZED BY CONTENT AND FORMAT (K, S, OR A) ....................................... A-1

APPENDIX B: CROSS CULTURAL SOCIAL PERSPECTIVE TAKING SURVEY ..... B-1

APPENDIX C: SURVEY RESULTS OF SPT ACADEMIC SMEs AND SOLDIERS ..... C-

APPENDIX D: INTERVIEW METHODOLOGY …............................................ D-1

APPENDIX E. DESCRIPTION OF THE FOUR PROPOSED CURRICULUM MODULES ……..................................................................... E-1

APPENDIX F. AN ASSESSMENT STRATEGY …............................................. F-1

\section{LIST OF TABLES}

TABLE 1. SPT RESEARCHERS’ AND SOLDIERS’ IMPORTANCE RATINGS OF PERSPECTIVE TAKING SKILLS

TABLE 2. TWENTY-TWO KSAs AND THEIR ACADEMIC SOURCES ..................... 18

TABLE C-1. SPT ACADEMIC SMEs’ SURVEY RESPONSES ................................ C-1

TABLE C-2. SOLDIER SURVEY RESPONSES …................................................ C-5

TABLE E-1. WHERE EACH KSA IS FIRST INTRODUCED IN THE CURRICULUM …................................................................................. E-2

TABLE F-1. ASSESSMENT TIMELINE AND GROUP COMPOSITION .................... F-1 


\section{SOCIAL PERSPECTIVE TAKING}

"Reflective senior officers returning from Iraq and Afghanistan are telling us that wars are won by creating alliances, leveraging nonmilitary advantages, reading intentions, building trust, converting opinions, and managing perceptions all these tasks demand an exceptional ability to understand people, their culture, and their motivation.”

Major General Robert H. Scales (Ret)

The current mindset of the Army is that it must be trained and able to win our Nation's wars while at the same time ready to assist in stability operations (U.S. Department of the Army, 2008). There is also recognition that "in any conflict, the population in the area of operations will be a key factor...” (U.S. Department of the Army, 2008, p. 1-4). A challenge is that U.S. Soldiers often have to bridge large cultural gaps and may lack the language skills to effectively engage with the host of individuals now present in the battlefield including the local populace, host nation security forces, coalition partners and other foreign governmental and nongovernmental agencies. Perspective taking is an interpersonal technique which can be used to address these challenges. Although perspective taking is a skill often learned throughout life, it can be very difficult to accomplish in cross-cultural interactions. For example, many Soldiers may have had no cross-cultural experience prior to deployment yet need to deal with complex issues related to tribalism, resource rights, and shifting alliances in-theatre (Masellis, 2009). Performed correctly, perspective taking allows the Soldier to consider the host national's perspective without cultural bias and erroneous assumptions. This process allows the Soldier to simultaneously meet host-national goals and accomplish U.S. missions and objectives.

While the academic literature provides insights into successfully applying perspective taking in various domains the challenge is to apply this information in a military, cross-cultural context. To do so our research effort involved the following objectives:

1. Conduct a review of the cognitive science, social science, psychology, and anthropological literature in the areas of education, medicine, and cross-cultural interactions.

2. Identify and classify the key perspective taking knowledge, skills, and attitudes (KSAs) gleaned from the literature review.

3. Conduct interviews with experts in the fields of social psychology, intercultural research, and medicine in order to determine the critical KSAs to be included in a training program.

4. Conduct interviews with Soldiers of various ranks to gather information concerning the contexts and situations Soldiers may utilize these KSAs.

5. Develop a curriculum for teaching perspective taking for a military audience based on the knowledge gained during activities.

The results of efforts are discussed in the following sections. 


\section{LITERATURE REVIEW}

As part of the literature review we gathered information on the definition of perspective taking, the steps or processes involved in taking the perspective of another, and what knowledge, skills, and abilities (KSAs) underlie one's social perspective taking ability in order to determine and make recommendations for a training system designed to develop perspective taking. The findings of the literature review will be discussed in the following sections.

\section{Definition of Social Perspective Taking}

Perspective taking has been defined as a skill requiring a combination of cognitive and affective/emotional skills and the propensity or motivation to engage in the activity (Gehlbach, 2004). According to Gehlbach, perspective taking consists of the strategies we use to figure out what others are thinking and feeling and their perception about situations. Johnson (1975) also notes that perspective taking requires a kind of social awareness: "Taking the perspective of another person is the ability to understand how a situation appears to another person and how that person is reacting cognitively and emotionally to the situation. It is the ability to put oneself in the place of others and recognize that other individuals may have points of view different from one's own” (p. 241). Perspective taking goes well beyond that feeling of resonance between two people and is an explicit representation of the other, by means of the cognitive and emotional resources of the self. The processes involved are subject to conscious control and thus can be modified by training and awareness.

To investigate the development of perspective taking many of the classic studies began with an examination of the developmental states of childhood (Piaget, 1924), scales of moral development (Kohlberg, 1969), and their combination into analyses of more complex models of development (Selman, 1971; Selman \& Byrne, 1974). For instance, Selman’s (1971) Five Stages of Perspective Taking posits that perspective taking begins with an undifferentiated notion of self, ages 3-6, and progresses rapidly to the early teenage stage of third-party perspective taking, ages 10-15, and to societal perspective taking (ages 14 to adult), where the teenager or adult can see how third-party perspectives are influenced by cultural norms and values.

According to Relational Frame Theory one's perspective taking ability begins with an egocentric orientation (Gillespie, 2006; Hayes, Barnes-Holmes, \& Roche, 2001) which is the natural perspective for both children and adults. Research demonstrates children remain more in an "I-Here-Now" perspective of the self while adults move to a "You-There-Then" frame of reference and back again to the egocentric orientation with great rapidity (Epley, Morewedge, \& Keysar, 2004). Individuals reference their own perspective a great deal, as it is the "home base" for understanding the perspectives of others.

Relational Frame Theory skills include the ability to enact what Gillespie (2006) calls "positional exchange." Examples of positional exchange that even young children understand and incorporate into their dramatic play include: give/receive; doctor/patient, order/obey; buy/sell; teacher/learner; feed/be fed; boss/worker; or care for/be cared for. Gillespie’s work 
focuses on how children in play routinely practice perspective taking in games such as hide and seek or tag, which almost always incorporate role exchange or reversal.

Taken together, many of the definitions and developmental theories of perspective taking incorporate an individual's sense of self or identity and the ability to project oneself in the role of another as important components of effective perspective taking. In the next sections we review evidence of the benefits and potential shortcomings of perspective taking and the process steps involved with taking the perspective of another.

\section{Benefits of Social Perspective Taking}

The benefits of successful perspective taking may include increased social understanding and harmony (Deutsch, 1993). In military settings, taking care of one's' Soldiers requires leaders to understand their subordinates (U.S. Department of the Army, 2006a) and to be successful in counterinsurgency environments requires U.S. forces to understand the enemy, the local populace and multinational partners and allies (U.S. Department of the Army, 2006b). Perspective taking promotes cognitive self-other overlap, results in less activation of stereotypes, and improves intergroup attitudes (Galinsky \& Moskowitz, 2000) and therefore leads people to do less stereotyping of “out-groups” and engage in less stereotype-driven fear and hostility resulting in reduced impulsive and aggressive behavior (Richardson, Green, \& Lago, 1998).

In addition, SPT fosters cooperation (Johnson, 1975), promotes moral reasoning and development (Hoffman, 2000), encourages altruistic behavior (Batson, Early, \& Salvarani, 1995), reduces prejudice (Rokeach, 1960), and facilitates conflict resolution (Deutsch, 1993). On a practical level, the understanding of others generally leads to better collaboration, social and awareness in a variety of ways in terms of needs assessment, planning, execution, oversight, and communication (U.S. Department of the Army, 2009). More essentially, accurate perspective taking may lead to trust, respect, and good relationships (see Ryan, 2008 for a description of how to build rapport with a host national counterpart). All of these benefits are relevant to success in the contemporary operating environment (U.S. Department of the Army, 2008)

\section{Potential Drawbacks of Social Perspective Taking}

Regardless of the many benefits of perspective taking there are several potential shortcomings and potential biases that may lead to faulty SPT. Occasionally, perspective takingrelated identification with another individual or group can lead to being linked to a disliked other, resulting in unwanted social or other consequences (Caruso, Epley, \& Bazerman, 2004). Also, if two parties engage in simultaneous perspective taking, social miscoordination might result from their joint effort to understand the other and find a middle ground for communication (Caruso et al., 2004; Galinsky, Ku, \& Wang 2005). Furthermore, perspective takers with low self-esteem tend not to be able to reduce their prejudicial attitudes toward other groups (Galinsky et al., 2005).

Likewise there are three ubiquitous biases which may lead to faulty SPT and include the fundamental attribution error (Ross, 1977), naïve realism (Ross \& Ward, 1995), and 
confirmation bias (Wason, 1960). The fundamental attribution error refers to peoples' tendency to overestimate the role of personality or individual characteristics and underestimating the role of context when assigning blame for other's failings (Ross). Specifically a person is likely to blame another individual for the individual's problems rather than attributing the problem to characteristics of the situation. However, people are likely to judge their own failings as being a result of the situation rather than themselves. The role of context therefore is a significant component of perspective taking, since an individual will need to consider all the factors when hypothesizing about the perspective of another person. Consequently, an objective of a training program on perspective taking should be to make trainees' aware of their tendency to overlook the role of context and of blaming the other person especially when dealing with a "very different other". Naïve realism is a tendency to believe that one sees objective reality (Ross \& Ward, 1995) whereas the other party does not. This bias often occurs in conjunction with wanting to preserve one's sense of self and the belief one is rational and correct in his or her perspective. In confirmation bias, individuals tend to seek out and select information that confirms theories they have previously developed since people usually want to prove themselves correct (Wason, 1960) and therefore may ignore information which conflicts with their assumptions.

In order to counter these potential drawbacks, a curriculum designed to train perspective taking must therefore take these issues into consideration as teaching and learning points in order to fully support the trainee's learning. In the following sections, we review the literature describing the steps or processes involved in taking the perspective of another.

\section{The Social Perspective Taking Process}

\section{Understanding the Self}

Self through the lens of personal experience. The self is where the process of perspective taking begins and incorporates one's sense of the world and one's sense of others. As noted by Decety (2005, p. 143)

“One's own perspective is the default mode (and the prepotent one) by which we relate to others. We see others as similar to ourselves on a variety of dimensions and consequently assume they act as we act, know what we know, and feel what we feel. This default mode is based on a shared representation mechanism between self and other...."

In order to function well in the world, one needs to be clear about who he or she is. This reflects a sense of agency - an understanding that one is the agent of one's own thoughts, feelings, and behavior (Decety \& Grèzes, 2006). Agency allows people to understand who has done what. When one has a strong awareness of their self, individuals are able to use it to imagine the thoughts and feelings of another person but still maintain a sense of agency (Decety \& Grèzes, 2006). Because people feel empathy for themselves, they have the capacity to feel empathy for others (Batson, 1991). For example, in a classic experiment (Batson, 1991), participants watched while someone whose hand was strapped into a machine received doses of "painful heat." One set of participants were told to remain objective and just watch while a 
second group was told to imagine how the target person was feeling. A third group was told to imagine being in the target person's place. The results indicated “objective” participants had less physical and emotional reaction of empathy to the target than did the other two groups. Crucially, none of the three groups was the least bit confused about who was self and who was other, indicating they maintained a sense of agency even as they engaged in taking the perspective of another.

Self-knowledge however is not necessarily accurate. People tend to believe their own views of themselves, although those perceptions may be distorted. Nonetheless, self-understanding is a great tool, as it helps people become better acquainted with the frame of reference they use when trying to understand other individuals. "We cognitively and emotionally refer first to ourselves, before we can imagine others, because we have such well developed and highly accessible, albeit often incorrect, theories of and knowledge about the self” (Van Boven \& Loewenstein, 2005, p. 288).

This imperfect self-knowledge is complemented by a beautiful ability to try to take the perspective of someone who will never be like us. For instance, if men are asked to imagine about giving birth and women are asked to imagine having testicular cancer, they can and do attempt the perspective taking leap (Halpern, 2001). Individuals can strive to know themselves better by inquiring into their own emotional and cognitive points of view, asking why they hold certain perspectives. This inquiry is a form of cognitive self-therapy, whereby a reflective person questions and challenges his or her emotionally influenced views of reality (Halpern, 2001).

Self through the lens of the American cultural perspective. One's sense of self or identity is a cultural construct of sorts (Markus \& Kitayama, 1994). People figure out who they are through extensive social interaction, first with their families and then with others. Individuals check their sense of who they are by comparing their identities with feedback they receive from those who know them. People tend to take great, if unconscious, comfort in having their ideas of self "continuously supported and affirmed by [their] culture group, that is by the natural, social and personal environment in which they have been nurtured” (Hoopes, 1979, p. 23).

When one relies too heavily on his or her own values, beliefs, and attitudes, he or she often makes perspective taking errors because other people will not have the same personality traits, personal history, or outlook on life, especially others from different cross-cultural contexts. Research demonstrates that relying too heavily on the self when engaging in SPT may lead to faulty hypotheses (Decety \& Grèzes, 2006; Jackson \& Decety, 2004; Ruby \& Decety, 2004) and our interviews with Soldiers confirm this; when individuals simply try to "put themselves in another's shoes," they can run into serious trouble since this overlap of self and other can be problematic (Galinsky et al., 2006). As noted earlier, it is very important individuals are clear on the question of agency and keep themselves sufficiently separate from the other party with whom they are engaging with. For successful perspective taking, it is imperative no merging, confusion, or sympathy (as opposed to empathy) arises (Vescio, Sechrist, \& Paolucci, 2003). 
People are often not very conscious of their cultural identity until they are in a cross-cultural context and are shocked into realizing that theirs is not the only culture in the world. It is helpful for the Soldier to explore - in broad brushstrokes - some of the values and behaviors associated with American culture, as well as how people from other cultures perceive us. There are a number of useful tools to help one understand American culture and its influence on thought and behavior. The new field manual Tactics in Counterinsurgency (U.S. Department of the Army, 2009) provides a cultural taxonomy or classification system for identifying the various influences, variations and manifestations of a given culture. For some individuals and Soldiers, a brief "reminder" sketch of American history may be helpful, along with a discussion of some of the different cultural dimension frameworks, such as those proposed by Hofstede $(1980,2001)$ and Klein (2004). These frameworks describe cultures at the societal level, using continua such as time, power, uncertainty, and individualism vs. collectivism. The individual or Soldier can consider himself and his country in light of these concepts, keeping in mind they are dimensions that relate to the societal level and may not adequately describe or represent all individuals from a culture.

An effective perspective taking training system should then include methods for the trainee to learn how to a) become aware of the ways in which they are culturally conditioned to certain views, values, and behaviors; and b) genuinely respect cultural differences and not assume their culture is better than any other culture

\section{Taking the Perspective of Someone Similar to Ourselves}

\section{Perspective Taking Theories}

Two common theories explain how one may go about taking the perspective of others. In simulation theory, "we mentally place ourselves in the other person's shoes, attempting to simulate what the target thinks.” (Reeder \& Trafimow, 2005, p. 111). In implicit theory, "we use our general knowledge and implicit theories about other people to infer the target's mental states” (Reeder \& Trafimow, p. 111). Experts argue it is likely both processes are simultaneously at work and people need imagination, empathy, cognitive skills and knowledge in order to make accurate perspective taking predictions (Reeder \& Trafimows).

As an example of how readily we attempt to place ourselves in another's shoes in one study people were asked to imagine an Alaskan backpacking trip gone horribly awry. Participants were then asked, "How would the hikers feel?" The study participants overwhelmingly answered, "If I were the hikers, $I$ would feel...." and although $79 \%$ of study participants described "mentally trading places with the hikers," they first mentioned vicariously imagining themselves as a hiker and only then went to the next step, which was active perspective taking (Van Boven \& Loewenstein, 2005). Further, this sort of perspective taking is limited by emotional states and any differences in the emotional states of the perspective taker and the other person (Van Boven \& Loewenstein, 2005). When people are in a "cold," non-emotional state, they do less well taking the perspective of someone in a "hot," emotional state, and vice versa. 
While some theorists have thought of the perspective taking process as a mental simulation in which we mentally place ourselves in the position of the other in the next section we will review some of the theories which view perspective taking as involving two discreet processing steps.

\section{Perspective Taking as a Two-Stage Process}

Some experts have considered perspective taking as a two-stage process. First, people predict how they might feel in another person's position. Second, they make adjustments to this prediction based on their understanding of how they are different from the target person (Van Boven \& Loewenstein, 2003). For instance, when asked to imagine how people lost in the desert for hours with no water would feel even though not thirsty themselves, research indicates people do not just imagine how thirst feels to another person but rather one imagines how he or she would feel if thirsty. The person then imagines the state of the other in that same context. This two-step process is a kind of compassionate projection.

Do people naturally and frequently engage in this sort of compassionate projection? Unfortunately, it appears that most do not. Instead, research indicates people are more likely to project their goals onto others without considering what is different about them and their needs (Kawada, Oettingen, Gollwitzer, \& Bargh, 2004). Experiments demonstrate adults tend to infer that others share their knowledge and beliefs even though they may rationally know it is unlikely to be the case (Keysar, Linn, \& Barr, 2003). If one does make adjustments to accommodate for interpersonal differences, it is usually because he or she makes a conscious effort to do so. Since many of the processes underlying perspective taking are not automatically engaged in when perspective taking, trainees' motivation to engage in such effortful processes needs to be increased in order for accurate perspective taking predictions to occur. Therefore, without the willingness to actively work through the perspective taking process even with others similar to ourselves we may opt for unconscious projection rather than conscious social perspective taking unless taught how to do it and why to do it.

Skills and attributes that can be used to enhance perspective taking and should be included in a proposed curriculum include:

- Cultivating self-awareness

- Being open, curious, and willing to take interpersonal risks

- Being able to cope with uncertainty

- Observing and listening carefully to the other person

- Cultivating empathy toward another person's thoughts and feelings, as a means to enhance perspective-taking

- Resisting snap judgments and delaying response

- Forming a perception and then checking its accuracy

- Inviting feedback and clarifying communication

- Taking action based on the entire process and the completed SPT communication loop

We will examine some of the skills and attributes, specifically interpersonal communication and empathy in more detail in the sections that follow. 
Interpersonal Communication. The literature is replete with examples of how interpersonal communication is crucial to SPT success. For example, a study published in the Journal of the American Medical Association notes that even before patients begin to tell their health stories, they give doctors verbal and nonverbal clues about their experiences and perspectives and when physicians offer detached or no responses, patients limit further communication (Levinson, Gorawara-Bhat, \& Lamb, 2000). In contrast, patient-doctor communications are enhanced when physicians respond by showing understanding and encourage patients to keep communicating. Success in counterinsurgency operations is similar in that vital communication and collaboration may or may not occur based on the Soldier's ability to create trust and openness in host nationals (U.S Department of the Army, 2006b).

Interpersonal communication skills are core components of SPT (Le Roux, 2002). To communicate effectively, Soldiers need to have good receptive, expressive, and communication repair skills (U.S. Department of the Army, 2006a). Language must be understood, whether directly or with the help of an interpreter. Deep listening skills include being able to listen for understanding, questioning and paraphrasing skills, and skills to check for cross-cultural understanding. Additional relevant skills (Willis, as cited in Yayang, 1993) include:

- Predicting what people are going to talk about or do

- Guessing at unknown words or phrases

- Using knowledge of the subject to help increase understanding

- Identifying relevant and ignoring irrelevant information

- Retaining relevant information (note-taking, summarizing)

- Recognizing discourse markers and cohesive devices

- Understanding intonation, stress, gestures, facial expressions, etc.

- Inferring, e.g., speakers' attitudes or intentions

Expressive communication skills are vital to the success of SPT (Byram, 1997; Halpern, 2001; Jandt, 2001). Studies have shown people are not nearly as effective in getting their messages across as they think they are (Halpern, 2001). In cross-cultural contexts, Soldiers can strive for simplicity and clarity where there is a language barrier by avoiding symbolic and figurative language when concrete language will do, articulating well, and using expressive nonverbal communication skills (NVC) to reinforce their message (see Artis, Keeney, Beltz, Reiter-Palmon, Brady, de Vreede, Sageman, \& Metcalf, under review for similar tips used by U.S. advisors when working with host national counterparts).

Individuals need good nonverbal decoding skills to effectively communicate with other individuals. When trying to understanding others, good nonverbal decoding skills are as important as verbal skills, as researchers argue that up to $70 \%$ of communication is expressed nonverbally (Mehrabian \& Ferris, 1967). Nonverbal skills span a broad range, from decoding universal and culture-specific facial expressions to kinesics (gesture, posture, expressions, eye contact, etc.), proxemics (use of space), paralinguistics (nonverbal utterances), chronemics (relation to time), silence, haptics (touch), territoriality, positions of people in groups, oculesics (eye-related communication), clothing, architecture and other contextual clues (Jandt, 2001). 
It is important to note individuals usually get feedback from others when they are not understood. In contrast, they rarely get unsolicited feedback when they are misunderstood. Thus, one must "check in" to ensure their message has been interpreted correctly. People make choices when they get into communicative trouble: they may give up on or revise their communication goals or they may try new strategies to succeed in communicating. Crucial skills that aid in communication understanding include message adjustment, clarification and confirmation requests, mime and gesture, appeals for help, paraphrasing, guessing from context, reactive communication that elicits new input, laughter, nonverbal expressions of empathy, and engaged body language (Byram, 1997; Matsumoto \& Juang, 2004).

Individuals need to communicate to determine whether their perspective taking is accurate or in need of further refinement or clarification (Frantz \& Janoff-Bulman, 2000; Halpern, 2001; Hardee, 2003; Hardee \& Kasper, 2005). Important communication skills needed for SPT therefore includes active listening, checking for understanding by using nonverbal cues, paraphrasing and mirroring, and asking questions that verify SPT accuracy.

Empathy and sympathy. Affective or emotional perspective taking is often discussed in educational, psychological, and medical contexts as being related to empathy and sympathy (Hardee, 2003; Vescio, Sechrist, \& Paolucci, 2003; Hatcher, Nadeau, Walsh, Reynolds, Galea, \& Marz, 1994). Because there are pitfalls inherent in identifying excessively with another person's emotional state, individuals should be taught the difference between empathy, a useful orientation, and sympathy, which can lead to a loss of healthy emotional boundaries.

The term empathy is thought to describe one's ability to identify with and understand another person's situation, feelings and motives. It is an understanding and to some degree a vicarious sharing while maintaining a sense of agency. It has been defined as "consideration of another [and] readiness to respond to his needs ... without making his burden one's own" (Szalita, as cited in Hardee, 2003, p. 2) while allowing the Army leader to better care for his Soldiers, their families and civilians (U.S. Department of the Army, 2006a). Scholars concur that empathy evolves along a developmental path along with cognitive and moral skills (Coke, Batson, \& McDavis, 1978; Hoffman, 1977).

Sympathy, on the other hand, refers to an experience of shared suffering where the borders between the two identities are blurred. Sympathy has thought not to be a desirable state or emotion, as it may lead to emotional burn-out, poor decision-making, and sometimes to pity, an emotion that entails condescension often experienced as disrespect and devaluing of another's personhood (Wilmer, 1968).

Empathy is not a form of abstract, theoretically-based reasoning, but is instead a form of knowledge that comes of experience (Halpern, 2001). It is related to the formation of concepts that help us understand other people. Empathy cannot be achieved through objective observation or detached inference, because that would indicate a lack of interpersonal connection and communication. True empathy - like perspective taking -- depends on a back and forth exchange between people that allows for information to be transferred, assimilated, felt, and tested for accurate understanding (Halpern, 2001). 


\section{Taking the Perspective of a Culturally Different Other}

Even if one has mastered perspective taking skills and is willing to use them, one must work with cross-cultural barriers to understanding. The following section examines the barriers and misunderstandings that can arise from variations in cultural patterns of thinking and communication. These cultural misunderstandings can lead to a decreased ability to establish trust and rapport.

\section{Ethnocentrism}

People are deeply and naturally ethnocentric. Ethnocentrism refers to considering one's own culture to be the referent for meaning-making and, to some degree, to be the one right culture. Individuals' ethnocentric beliefs shape their own identities, encourage them to make judgments about others through the filter of their cultural beliefs, and may cause them to elevate their culture above all others (Stewart \& Bennett, 1991). Ethnocentrism may lead to stereotyping people of a foreign country - a way of assuming similarities among them and overlooking differences (the out-group homogeneity bias). While ethnocentrism is a natural process it nonetheless may cause harm to relationships and result in cultural misunderstandings (Odom, 2007).

To overcome one's native ethnocentrism, Hoopes (1979) argues individuals can undertake a series of steps in the following order:

- Cultivate awareness of other cultures

- Understand cultural relativism and difference

- Accept and respect those differences

- Appreciate and value those differences

- Adopt new attitudes and behaviors, including ones that support cultural assimilation

- Assimilate and acculturate

Without knowledge of another person's culture, however, a Soldier may “project” his own cultural experience onto the other person. Being able to analyze interactions for cultural components is important, and can include specific cultural knowledge, cultural cognitive bias, culture-specific nonverbal behaviors, and other dynamics. Even when cultural knowledge is available misinterpretations are commonplace in cross-cultural interactions and may result in misunderstanding and miscommunication. With the addition of the communication and perspective taking skills outlined above to a baseline of cultural knowledge, an individual will be able to gain access to the other person's perspective, become cognitively aware of it as an educated guess, confirm whether he is right or wrong, and take action accordingly.

Here is an example taken from interviews with Soldiers of the failure to take the perspective of the key party and failure to follow up with verifying communication (E.Woloson, personal communication, June 6, 2007).

In Indonesia, a physician provides care to a small village by visiting once a month. He works his way along the main street, where villagers line up outside their houses and wait 
patiently for him to reach them. However, because he works his way along the street from west to east every time and because so many people need care, only half of the villagers ever receive care. Those on the west end of the village are consequently much healthier than those on the east, who resort to black magic to cure their ailments. An American military officer stationed nearby is concerned about this public health problem. She organizes a village meeting to try to find a solution to the problem. At the meeting, it is decided that the doctor should work from east to west along the main street every other month, to make the care provision fair for all. However, nothing changes. Why?

The Army officer forgot to include the physician in the needs assessment and planning, and thus did not take his perspective into account. The power structure in Indonesia and many other countries is not based on consensus, but on who has the most clout. The physician can do what he wants to do because he is revered in the culture. It turns out that he has relatives on the west end of the village and enjoys their hospitality. He also knows the west end families better and feels more comfortable with them. No change is possible unless he agrees to it.

As seen from the story the Army officer failed to consider the doctor's viewpoint and perspective in developing a solution. Therefore it is important one does not make quick decisions based on their own perceptions and what feels "right" to them but must take into account the likelihood others will perceive the problem and potential solutions differently through their personal and cultural lens.

\section{Respect For and Valuing Of Others}

One of the Army's seven basic values is respect (U.S. Department of the Army, 2006a). According to doctrine respect means to treat others as you would be treated and refers not only to the treatment of those like us but also those from other cultures (U.S. Department of the Army). Additionally to work effectively with host nationals and support SPT it has been demonstrated Soldiers need to cultivate respect for the dignity, value, and autonomy of the people with whom they are working with cross-culturally (Ryan, 2008; U.S. Department of the Army, 2009).

\section{Emotional Regulation}

Self control influences one's ability to interact effectively with others (U.S Department of the Army, 2006b). Emotional regulation is a set of processes - physiological, affective, cognitive, and behavioral - by which emotions can be managed or modified. Emotional regulation involves an understanding of one's own patterns of emotional reactivity, and an ability to take steps to regulate emotion in ways congruent with one's needs and goals. This can be done in the antecedent phase (anticipation/preparation phase) or in the reaction to stimulus stage. The antecedent-focused stage concerns the things that one does before an emotion starts that affects whether a given emotion occurs. The reaction to stimulus stage occurs when a certain emotion has already been triggered (Gross \& Munoz, 1995). Antecedent -focused emotional regulation processes are better than reaction to stimulus emotional regulation processes in terms of reducing negative emotion and unwanted physiological response (Mauss, Bunge, \& Gross, 2007).

Research has shown that when people are primed to behave a certain way, they are more likely to 
do so (Mauss, Bunge, \& Gross, 2007). The Army can help its Soldiers internalize emotional and behavioral goals that will help them to successfully engage in emotional regulation and make them more successful in perspective taking.

Emotional regulation is a crucial skill for successful SPT and is frequently overlooked (Matsumoto \& Le Roux, 2003; Matsumoto, Le Roux, Bernhard, \& Gray, 2004). Although emotions are necessary to engage in successful SPT, if emotions are allowed to interfere with cognitive processing they may cause faulty SPT (Canli, Zhao, Brewer, Gabrieli, \& Cahill, 2000). Misunderstandings and conflict are a frequent and natural byproduct of cross-cultural interactions. Because misunderstandings in turn frequently lead to negative emotions, emotional regulation is key to allowing critical thinking about the relevant cultural issues and cognitivebehavioral adaptation to the context (Matsumoto \& Juang, 2004). Emotional regulation serves as a way of anchoring the self to address and adjust for cultural differences (Mendoza, 1997; Roeser, Eccles, \& Strobel, 1998). Trainees should be made aware that emotional regulation is an essential step before and during SPT and taught how to regulate emotions. In short, training should teach the individual to self-scan, anticipate, label one's emotions, and stop the process of emotional escalation through behavioral and cognitive techniques (Matsumoto, Yoo, \& Le Roux, 2007).

It is important emotional regulation not be mistaken for emotion repression as repression often leads to decreased recognition of an expression of emotion, but not necessarily a decrease experience of emotions (Gross, 1999). In fact, emotional repression has been correlated with greater physiological arousal, which can lead to higher cortisol levels and excess sympathetic nervous system activity (Gross, 1999) and may lead to job strain and job burnout (Grandey, Fisk \& Steiner, 2005). Complete emotional detachment is also problematic, as SPT requires a degree of personal engagement with another person or group. One cannot depend on one's "objectivity" and pure reason to gain an accurate understanding of others (Halpern, 2001).

The roles and processes of emotion and cognition are very much intertwined. For example, emotions may influence our cognitions and our cognitions have a role in the generation and identification of emotions and emotional regulation. Although emotions are sometimes viewed as a hindrance to the cognitive processes involved with perspective taking, emotions are necessary to enhance memory consolidation (a cognitive process) which is needed for SPT (Canli, Zhao, Brewer, Gabrielli, \& Cahill, 2000). Further, emotional reasoning is a useful term for describing "emotion-guided thought processes" and differentiates this type of reasoning from purely logical, detached reasoning (if indeed there is such an isolated thinking form) (Halpern, 2001, p. 11). Emotional reasoning involves "associational thinking" where one person is able to engage with the mental and emotional associations of another person and change his or her own associations to incorporate them.

\section{Reliance on Cultural Knowledge Alone}

As noted earlier, cultural dimensions can be a useful tool for developing a general understanding of one's culture and the culture of other individuals. However, these dimensions should not be overly applied or used to describe individuals as they are only a general framework for considering societal-level differences (Burke, Hess, Priest, Rosen, Salas, et al., 2005). 
Stereotyping may be an unanticipated consequence of categorizing whole cultures based on cultural dimensions (Osland \& Bird, 2003). In reality, cultures are complex and individuals within a culture vary widely. Because perspective takers may rely on stereotyping already when dealing with a target they view as dissimilar (Ames, 2004), promoting the use of cultural knowledge as one's main means of extracting what the other is thinking may be potentially detrimental to the perspective taking process. What is needed for successful perspective taking is a process which uses cultural information as one source of information, in addition to and in conjunction with other kinds of knowledge and SPT skills. Therefore it may be argued that the use of cultural dimensions as the sole method to understand others may limit one's understanding and perception of others.

\section{In-group/Out-group Bias}

Studies reveal people have strong biases in favor of "in-groups" in which they are members, and tend to mistrust, fear, and stereotype "out-groups” with which they are unfamiliar (Tajfel, 1970). Understanding one's own identity and values, including one's sense of membership in groups and ways of perceiving groups, helps lay the groundwork for willingness to engage in SPT. Without this understanding and without clear incentives to learn and use SPT, a Soldier might seek to avoid cross-cultural interactions.

As part of understanding his identity, an individual needs to see how his sense of self differs from that of others he knows such as his friends, family and coworkers. In addition, it is very important to identify and explore the groups he is a member of. How does he perceive these groups and what is his relationship to them? Fellow in-group members wield considerable influence over how one sees him or herself. People may define their abilities in relation to the in-group (Miller \& Prentice, 1994) or be influenced by their emotional bonds with the group (Brown, Novick, Lord, \& Richards, 1992).

Research indicates a person becomes more positive toward the members of groups to which he or she belongs (in-group bias) and is likely to treat members of other groups less well (outgroup bias) (Brewer, 1979). People tend to associate in-group members with positive traits and associate negative traits to out-group members (Brewer, 1979) Individuals also tend to overestimate how similar fellow in-group members are and perceive out-groups to be more different from themselves than they actually are (Gehlbach, 2004). They may even believe members of out-groups are very similar to each other thereby minimizing out-groups individual differences. This is known as the out-group homogeneity effect and may lead to unhelpful stereotypes. SPT is particularly vulnerable to error with out-groups because people tend to rely on stereotypes. Ames (2004) developed a model of "mind reading” that included social projection and stereotyping. He found that when perceivers assume an initial general sense of similarity to a target, they engage in greater projection and less stereotyping (Ames, 2004). Also, Kunda, Davies, Adams, \& Spencer (2002) demonstrated that stereotyping declines as a person becomes accustomed to a group he tends to stereotype, but that stereotyping can flair up again if the person gets in a disagreement with a member of the previously stereotyped group. 
In cross-cultural contexts, the in-group loyalty of the Army unit can be very helpful, but stereotyping of and prejudice toward out-groups may impair Soldiers' ability to succeed in military operations (U.S. Department of the Army, 2009). According to Epley et al., (2004) individual and in-group biases create a tendency for the individual to:

- Overestimate the degree to which others share their feelings/attitudes

- Believe others have more access to their internal states than they actually do

- Use their own knowledge as a guide to what others know

- Use themselves as a standard when evaluating others

- Focus too much on their own experience when anticipating being evaluated by others

The proposed training therefore aims to raise the awareness of and mitigate unconscious biases in Soldiers. As the Soldier explores the groups in which he is a member, he sees how each has its own emotional and cognitive culture, and he gains perspective on how these factors may affect his perceptions and assumptions.

\section{Cross-Cultural Communication}

Many countries where the U.S. Army is currently active, e.g., Iraq and Afghanistan, are considered high-context and collectivist cultures and may favor indirect styles of communication (Jandt, 2001). Cross-cultural communication in general is characterized by a higher level of conflict and misunderstanding than same-culture communication (Matsumoto \& Juang, 2004). Cross-cultural conflict in turn may increase uncertainty, stress, and frustration, and produce other negative emotions and evaluations (Matsumoto \& Juang, 2004). Increased uncertainty and frustration is highly detrimental to SPT processing, as uncertainty leads to ambiguity and a tendency to distort perceptions (Pusch, 1979). Learning how to reduce uncertainty should be a major goal of training and can be achieved by teaching individuals to engage in the following behaviors as suggested by Pusch (1979):

- Take extra time in communication

- Engage in more active listening, mirroring, and "back translation” to confirm mutual understanding

- Be highly aware of nonverbal cues/channels and the meaning of silence

- Use additional confirming sources of information/interpretation where possible

- Question tactfully and in the context of culturally acceptable communicative behavior

- Engage in extra exchanges to confirm meaning and mutual understanding

In the intercultural communication process, cultural differences such as uncertainty avoidance, relationship to time, power and gender dynamics, and individualism vs. collectivism are likely to come into play. The perspective taker's goal is to create a shared understanding of the work with his target, however briefly, so he can successfully verify SPT and enhance crosscultural relationships (Byram, 1997). Perspective taking therefore requires an ability to limit ethnocentric or stereotypic perceptions and build on common ground in order to "mediate between conflicting interpretations” (Byram, p. 52). What may feel like redundancy or repetition in a same-culture interaction is essential to cross-cultural communication, and especially to SPT (Pusch, 1979). 


\section{SURVEYS AND INTERVIEWS TO VET KSAS FROM ACADEMIC LITERATURE}

\section{SPT Academic SME Surveys and Interviews}

The literature review produced a list of $41 \mathrm{KSAs}$ applicable for this effort and is presented in Appendix A. In addition to the literature review, a qualitative survey consisting of a list of the $41 \mathrm{KSAs}$ was created and sent to 20 researchers with expertise in either cultural competence or interpersonal psychology (a copy of the survey can be found in Appendix B). The participants were prominent researchers in their areas as determined from the literature review. The research team identified the twenty perspective taking authors who published the most frequently in juried journals and contacted them through email. The purpose of the survey was to assess SME reactions to the importance of the 41 KSAs extracted from the literature and to determine which were primary to social perspective taking in order to make the number of KSAs teachable in the time allotted. The participants were asked to rate each of $41 \mathrm{KSAs}$ as either essential (1), important (2), or unimportant (3) to developing SPT aptitude. Participants were limited to no more than twenty \#1 responses (essential) to determine which KSAs were most crucial. Five open-ended questions involving their opinion about the KSAs followed. Because of the small sample size, no quantitative analyses were conducted (participants' responses can be found in Table C-1 of Appendix C) however qualitative information was enlightening and helped winnow the initial KSA list. Survey responses indicated high concurrence on the importance of the following social perspective taking skills:

- Employs effective people-observing skills

- Employs effective nonverbal communication skills

- Checks for understanding in a cross-cultural exchange

- Understands consequences of faulty perspective taking

- Asks questions to check interpretation before making decisions about next steps

- Understands the notion that one culture is not better than another

- Understands that some judgments the Soldier makes about host nationals and vice versa have their basis in general cultural differences

- Understands that a behavior can be interpreted differently based on culture

- Understands differences in thinking based on religion

- Anticipates areas of potential conflict based on thinking differences

A common theme in the open ended questions included the need for making Soldiers aware of their own biases and the need for "checking-in" when attempting SPT. In fact, all respondents mentioned this theme of understanding our own patterns of biased thinking. All respondents also mentioned the need for making esoteric concepts real.

An iterative process of in-depth telephone interviews then occurred with all respondents in which multiple call-backs to participants were made to clarify prior answers and to answer new questions as they emerged (See Appendix D for more detail about the research interview methodology). The iterative process was based on informal, open-ended questions to extract more details about SPT and the best methods to teach SPT. The respondents elaborated on responses from their surveys and discussed their view of what was crucial for SPT effectiveness. 
A majority of researchers described that an ideal method for teaching SPT should be case study and/or role play.

\section{Soldier Surveys and Interviews}

Besides the SME survey and interviews, 10 email invitations to Soldiers were sent inviting them to participate in a survey and phone interview about their experiences. Eight Soldiers replied and phone interviews were conducted with seven of the Soldiers and one participated in a video-taped interview. The Soldiers' ranks included; two Lieutenant Colonels, two Majors, one Captain, one Sergeant, and two Military Attaches. All had been deployed to Afghanistan or Iraq with the exception of one participant who had served in Vietnam and Africa. These Soldiers also provided the names of interpreters with whom they had served. Four interpreters were subsequently interviewed based on informal questions to extract details about their individual experiences with SPT while working with Americans overseas. Of the eight Soldiers who participated in the interviews, four of them also completed the same survey as the perspective taking researchers and their responses can be found in Appendix C. A general description of the findings from the Soldier surveys and interviews can be found below.

Again, due to the small number of respondents, a quantitative analysis was not conducted. However, of the four Soldiers that completed the survey, there was unanimous agreement on the following skills as being essential to perspective taking:

- Employs effective nonverbal communication skills

- Understands differences in thinking based on religion

- Anticipates areas of potential conflict based on thinking differences

Additionally Soldiers felt the following skills were important to the development of perspective taking:

- Understands that some judgments the Soldier makes about host nationals and vice versa have their basis in general cultural differences

- Understands that a behavior can be interpreted differently based on culture

The participants' noted that it was unimportant for Soldiers to "Understand[s] the notion that one culture is not better than another".

Additionally a comparison was made between what perspective taking skills the SPT subject matter experts and Soldiers thought was important or essential for the development of perspective taking. Some examples follow in Table 1: 
Table 1

SPT Researchers' and Soldiers' Importance Ratings of Perspective Taking Skills

\begin{tabular}{|l|c|c|}
\hline Perspective Taking Skill & $\begin{array}{c}\text { Importance Ratings of } \\
\text { SPT Researchers }\end{array}$ & $\begin{array}{c}\text { Importance Ratings } \\
\text { of Soldiers }\end{array}$ \\
\hline Employs effective people-observing skills & Essential & Important \\
\hline $\begin{array}{l}\text { Employs effective nonverbal communication } \\
\text { skills }\end{array}$ & Important & Important \\
\hline $\begin{array}{l}\text { Checks for understanding in a cross-cultural } \\
\text { exchange }\end{array}$ & Important & Important \\
\hline $\begin{array}{l}\text { Understands that a behavior can be } \\
\text { interpreted differently based on culture }\end{array}$ & Essential \\
\hline $\begin{array}{l}\text { Anticipates areas of potential conflict based } \\
\text { on thinking differences }\end{array}$ & Important & Important \\
\hline
\end{tabular}

Consequently, the original list of 41 KSAs was winnowed to a list of 22 KSAs based on what seemed most germane from the literature as well as the researcher and Soldier interviews and survey results. The final list is shown in Table 2. 
Table 2

Twenty-two KSAs and Their Academic Sources

\begin{tabular}{|c|c|}
\hline Primary Knowledge & Research Citation on Specific KSA \\
\hline $\begin{array}{l}\text { Understand Social Perspective Taking concept and relevance } \\
\text { to successful intercultural communication and to mission } \\
\text { success }\end{array}$ & $\begin{array}{l}\text { Galinsky et al., 2005; Galinsky \& } \\
\text { Moskowitz, 2000; Gehlbach, 2004; Epley } \\
\text { et al., } 2004\end{array}$ \\
\hline Recognize fundamental attribution error & Vescio et al., 2003; Ross, 1977 \\
\hline Recognize naïve realism & Armstrong, 1961; Ross \& Ward, 1995 \\
\hline Recognize confirmation bias & Gilbert \& Malone, 1995 \\
\hline Understand consequences of faulty perspective taking & Malle \& Hodges, 2005 \\
\hline Understand the impact of in-group/out-group bias & $\begin{array}{l}\text { Caruso et al., 2004; Devine, 1995; } \\
\text { Brewer, } 1979\end{array}$ \\
\hline $\begin{array}{l}\text { Understand how one’s ideas, values, thoughts, and identity } \\
\text { are influenced by multiple factors, including culture }\end{array}$ & $\begin{array}{l}\text { Decety \& Chaminade, 2003; Matsumoto, } \\
\text { \& Juang, 2004; Byram, 1997; Hall, } 1959\end{array}$ \\
\hline \multicolumn{2}{|l|}{ Secondary Knowledge } \\
\hline Understand how culture influences perception & Chandler, 2005; Matsumoto, 2004 \\
\hline Understand the pitfalls of stereotyping & Ames, 2004 \\
\hline $\begin{array}{l}\text { Understand the notion of cultural relativism and that one } \\
\text { culture is not better than another }\end{array}$ & $\begin{array}{l}\text { Earley \& Ang, 2003; Elkhamri, 2007; } \\
\text { Matsumoto \& Juang, } 2004\end{array}$ \\
\hline \multicolumn{2}{|l|}{ Primary Skills } \\
\hline $\begin{array}{l}\text { Regulate emotions before and during cross-cultural stressful } \\
\text { communication exchange }\end{array}$ & $\begin{array}{l}\text { Gross, 1998, 1999, 2006; Gehlbach, } \\
\text { 1999; Matsumoto \& Juang, } 2004\end{array}$ \\
\hline $\begin{array}{l}\text { Extract cultural and contextual data through: observing, } \\
\text { listening, questioning, \& interpreting nonverbal behavior }\end{array}$ & $\begin{array}{l}\text { Byram, 1997; Dixon \& Moore, 1990; } \\
\text { Dornyei \& Thurrel, } 1991\end{array}$ \\
\hline $\begin{array}{l}\text { Develop tolerance for uncertainty and the ability to postpone } \\
\text { judgment }\end{array}$ & $\begin{array}{l}\text { Gehlbach \& Brinkworth, in press; Ickes, } \\
1997\end{array}$ \\
\hline Correct for biases & Gehlbach \& Brinkworth, in press \\
\hline Develop multiple hypotheses (2-3) during SPT attempt & $\begin{array}{l}\text { Griffin, Dunning, \& Ross, 1990; Decety } \\
\text { \& Grèzes, 2006; Decety \& Sommerville, } \\
2003\end{array}$ \\
\hline Check for accuracy of SPT hypotheses & Pelias, 1984; Wason, 1960; Winner, n.d. \\
\hline Confirm/disconfirm hypotheses & Gehlbach \& Brinkworth, in press \\
\hline Adapt behavior based on chosen hypothesis & Hardee, 2003; Hardee \& Kasper, 2005 \\
\hline Gather feedback on one's action & Hardee, 2003; Hardee \& Kasper, 2005 \\
\hline Use cultural knowledge to influence hypotheses & Malle \& Hodges, 2005 \\
\hline \multicolumn{2}{|l|}{ Primary Attitudes } \\
\hline $\begin{array}{l}\text { Have the motivation and persistence to engage in SPT } \\
\text { activity: Develop disposition to engage in SPT frequently; } \\
\text { Be motivated to persist in SPT under challenging conditions. }\end{array}$ & $\begin{array}{l}\text { Gehlbach, 2004; Eccles, 1984; } \\
\text { Brown et al., 2006 } \\
\text { Corno, Cronbach, Kupermintz, Lohman, } \\
\text { Mandinach, et al., } 2002\end{array}$ \\
\hline \multicolumn{2}{|l|}{ Secondary Attitudes } \\
\hline Be open to other cultures & $\begin{array}{l}\text { Pusch, 1979; Lewis, 2006; Fowler \& } \\
\text { Mumford, 1995; Fowler \& Mumford, } \\
1999\end{array}$ \\
\hline
\end{tabular}




\section{TEACHING METHODOLOGIES FOR SPT}

As part of the literature review, we also investigated the teaching methodologies used to improve social perspective taking. From this review, we found that a number of teaching methods for SPT and related communication and cultural competency skills have been used effectively. In particular, the GlobalEd Project at the University of Connecticut performed simulations with middle and high school students to examine how students' best improved their SPT skills (Brown, Gehlbach, Ioannou, Boyer, Hudson, et al., 2006). Their results indicate practicing SPT in heterogeneous (mixed gender) groups results in better achievement outcomes than practicing in homogeneous groups (Brown et al., 2006) These findings are encouraging for the Army given the Army’s increasing heterogeneity (U.S. Department of the Army, 2006a). Several of the teaching methodologies will be further discussed below.

\section{Videotape}

Videos of cross-cultural perspective-taking interactions have been shown to be effective in teaching SPT in classroom-based settings. (Hartley \& Hopkins, 1999). Students witness crosscultural interactions and engage in vicarious cross-cultural extraction and interpretation, actual hypothesizing, bias issues, and verification and action paths. This method helps identify deepseated cultural beliefs that interfere with communication and interpersonal trust.

Live video with playback is also an excellent teaching tool. Ickes, Stinson, Bissonnette, and Garcia (1990) have utilized this method by videotaping two participants in an unstructured interaction who are then asked to a) report on their own thoughts and feelings, and b) infer those of the other participant. With the instructor's help, the two sets of thoughts and feelings are compared and coded for accuracy. Ickes et al. assert this is a reliable method for practicing SPT and evaluating the abilities of participants.

\section{Case Studies}

Case studies are accounts - either written or audio-visual - of real or realistic scenarios. The benefit of case studies is they can be more detailed and complex than scenarios used in other teaching methods (Lacy \& Trowbridge, 1995). Real life situations offer experiences and information quickly, efficiently, experientially, and meaningfully (Rippin, Booth, Bowie, \& Jordan, 2002). The method helps students implement theory in contexts that mimic real life situations (Jennings, 1996; Metcalf \& Zbylut, 2007) and also work effectively with adjunct pedagogical methods such as discussion, role play, and exercises (Zbylut, Brunner, Vowels, \& Kim, 2007).

\section{Role Plays}

In a role play, two or more participants "take on characteristics of people other than themselves” (McCaffery, 1995, p. 19) and the purpose of the role play is to build skills, such as the KSAs involved in improving SPT. Role plays allow participants to engage in experiential learning with other people, practice skills, engage in self-reflection, and receive feedback from observers. Dialogues also work well with role plays because trainees can experience a problem- 
based dialogue, perhaps in the third person, and then role play a more successful version in the first person (Storti, 1999).

In medical schools, a technique using "standardized patients" has given way to the use of "care actors" to teach cross-cultural communication and relationship-building skills. Students are presented with a sample problem or scenario and are then given time to practice a set of skills (such as SPT), and receive feedback concerning their performance. Instructors can stop students at any point and instruct them to "stop, rewind, and try again." This medical context communication technique includes four specific steps: a thoughtfully-planned scenario; a communication strategy and a goal; identification of emotions and thoughts of the other person; and evaluation (Hardee \& Kasper, 2005).

\section{Branching Exercises}

A video-based short scenario can be accompanied by a set of "branching" choices, one of which in each branch helps a Soldier choose an action path or hypothetical line or reasoning. Branching works well with computer-based training, as it can be designed to offer trainees feedback loops and individualized remediation and has been used for formative and summative assessments (Wight, 1995). For cross-cultural training purposes, the critical incidents can be constructed so accurate perspective taking helps participants move toward choices regarding action. Attributions or explanations are followed by feedback from experts in SPT or Soldiers with cross-cultural experience (Triandis, 1995). These scenarios can be tailored to fit individual Soldier's rank and assignment. Ideally, they are excellent practice for individualized selfdevelopment and may be used by Soldiers in school-house if computers are available (Carter, 2005; Furstenberg, Carter, Henderson, \& Ahles, 2002).

\section{Pair Share of Small-Group Discussion and Exercises}

Pair share or small group discussions are effective "schoolhouse" tools for exploring the gap between the self and others and for making individuals aware of group dynamics/bias issues. As groups are cultures in their own right, it is best to let a group organize itself and reflect on its own nature (McCaig, 1999). Individual "stand alone" students could also access this method if they participate in an on-line SPT chat room or share SPT observations with another student asynchronistically (Carter, 2005; Furstenberg et al., 2002).

\section{A PROPOSED CURRICULUM FOR SOLDIERS TO LEARN SPT SKILLS}

Based on the knowledge gained during the literature review of the underlying KSAs of social perspective taking and of the teaching methodologies used for training SPT, and supported by the results of interviews with SMEs and Soldiers, we developed a four module curriculum for training SPT. The curriculum was defined for two specific instructional contexts: classroom discussion and stand-alone instruction. Specifically the curriculum contains four modules (see Appendix $\mathrm{G}$ for a greater description of the four modules): 
- An Introduction to Perspective Taking;

- Exploration of the Self;

- Perspective Taking with a Similar Other; and

- Perspective Taking with a Culturally Different Other.

In the proposed curriculum KSAs related to teaching SPT follow the trajectory from the individual to a similar other to a very different, cross-cultural other. Similarly, an "in-group" focus will evolve through structured learning activities to an "out-group" focus. Before the Soldier can benefit from the SPT skills that spiral outward from understanding the perspective of self to that of a similar other and then a very different, cross-cultural other, he must be willing to attempt perspective taking.

Given limited time in pre-deployment training, decisions had to be made as to what would give the Army the most return on its investment. Soldiers already receive culture-specific training and the Army is putting in great resources to supplement this training with culturegeneral training. Given this emphasis already in place, it became imperative to ask, "How will a Soldier use this cultural knowledge to make sense of the cultural context in which he finds himself?" and "How can he use it to better understand and build relationships with host nationals with whom he comes in contact?” A model for using this cultural knowledge became the centerpiece of the curriculum.

The curriculum teaches Soldiers how to use cultural knowledge, along with other KSAs and situational contexts, to help decode behavior they observe through questioning, hypothesizing, feedback, and verification. Although not necessary because of the cultural information extraction techniques taught, it is recommended Soldiers begin this curriculum with some culture-general and culture-specific knowledge.

This curriculum provides Soldiers a framework to use all kinds of information in order to "read" an individual's thoughts and motivations. It encourages Soldiers to slow down and not to decide on meaning or take action prematurely. It teaches Soldiers to understand the limitations of their assumptions and gives them tools for turning erroneous assumptions into a means to extract and understand the perspective of the other person and to verify that understanding. It leads the Soldier to ask him or herself if he or she needs to adapt behavior based on SPT verification to accomplish mission goals. By showing how helpful SPT is to relationshipbuilding and mission success, it increases propensity to engage in the steps involved in achieving accurate SPT.

\section{Propensity: Motivating the Soldier to Learn SPT}

Propensity is defined as a willingness to do and a likelihood of doing something (Gehlbach, 2004) and has been shown to correlate positively and strongly with attitude (Gehlbach, 2004). Propensity to engage in SPT is related to anticipation of being successful at it and gaining some benefit from it. Propensity toward perspective taking in a cross-cultural context is increased by a skill set that includes emotional regulation, openness, flexibility, creativity, and critical thinking ability (Gehlbach, 2004). Fortunately, attitudes can be changed or adjusted by motivating factors 
and incentives (Eccles, 1984; Gehlbach, 2004; Howard, 1989). Curiosity about people from other cultures is also helpful, as is tolerance of ambiguity and uncertainty (Rossing \& Long, 1981).

Presented with the professional and personal benefits of SPT, Soldiers can be motivated to improve their skills (Earley, 2004). For Soldiers, the need to enhance the safety, well-being, and success of the unit is often a very powerful motivator (Rossing \& Long, 1981). Soldiers also want to be respected and valued by their fellow Soldiers. In training the trainers, the proposed curriculum will seek to help them quickly get to know their Soldiers and help them maximize their individual propensities. The rewards for good performance include improved ability to meet the needs of the Army.

\section{The Four-Step Method}

The proposed curriculum is designed to teach a four-step social perspective taking method that Soldiers can use in the field. The method is simple, flexible and can be utilized in a variety of settings. It is easy to memorize, but requires practice, and is most effective when the Soldier communicates with the host national to try to verify his lead hypothesis about what the other person is thinking and feeling. Closing the communication loop greatly enhances the chance of accurate SPT.

Trainees will learn the following four-step method through video cases and will implement and practice related KSAs through activities including individual work, pair work, group discussion, branching exercises, and role play. A description of the four steps follows below.

\section{Step 1. "You don't know what you don't know"}

Research demonstrates individuals are frequently incorrect in their SPT hypotheses when they rely heavily on their own experience and values and fail to glean information from the other party (Ames, 2004; Frantz \& Janoff-Bulman, 2000). Therefore, Soldiers must be aware of what they do not know and that their initial guesses regarding another's behavior may be wrong (Ross, 1977; Yayang, 1993). Trainees must also be aware of how the relationship between the two parties - especially in cross-cultural interactions - can affect SPT (Drolet, Larrick \& Morris, 1998; Ickes, 1997; Ickes et al., 1990;). Therefore, Soldiers will be trained to engage in culturally sensitive questioning, deep listening, mirroring, and verification of information.

\section{Step 2. “Consider self, then other”:}

The Soldier makes use of his knowledge of self, his own cultural and personal biases, and his knowledge and observations of the other person extracted in Step 1. The Soldier must go beyond his initial hypothesis to one or two additional hypotheses based on information from the other person (Chamberlin, n.d.). This act forces him to think critically and flexibly about the other person in the other person's context. In this step, Soldiers will learn to self-check for emotional regulation followed by adjusting for cultural and other differences between self and other. The Soldier will create two or three hypotheses about the other person's perspective. 


\section{Step 3. "Check in"}

Communication is used to check understanding, create common ground, modify hypotheses, and disprove and discard erroneous ones. In this step the Soldier will communicate through questions and mirroring with the other person, and modify hypotheses as needed (Hardee, 2003; Halpern, 2001). This step involves the conduct of a dynamic conversation that opens the communication channels for better understanding through:

Communicating Through Questioning and Mirroring- the Soldier makes sure he or she engages in thoughtful inquiry, and parrots back to his or her conversation partner what it is he or she thinks they're saying.

Modifying Hypotheses as Needed - As the Soldier gathers additional information, he or she may change his or her understanding and estimation of the truth. Hypotheses are then rebuilt, if needed.

It is important trainees continue to practice emotional regulation throughout this step.

\section{Step 4. "Invest in outcome"}

Soldiers may find increased interpersonal trust and rapport by capitalizing on hypothesis verification. By verifying and validating what a Soldier thinks he or she understands, he or she can adjust the conversation accordingly so that mission goals are more likely to be met. The Soldier will seek solutions to meet mission success through confirming hypotheses and then adapting behavior if doing so will increase likelihood of mission success. Investing in making sure one is correct in his or her assumptions, and then following through to make sure all involved are similarly aligned, should aid the Soldier in accomplishing the task at hand.

Published and presented work on aspects of the four-step method confirms it helps to resolve conflicts and increase historical empathy, an understanding of how the past affects the present of a cultural group (Gehlbach, 2004). The method addresses trainee motivation through the use of various propensity elements (Corno et al., 2002; Eccles, 1984; Snow, 1996). The four-step process has been shown to be an effective teaching method and works well with motivated and sophisticated trainees who can still make a range of cognitive mistakes (Gehlbach). In related work, the GlobalEd project at the University of Connecticut has shown that use of the method produced increased accuracy and proficiency in cooperation, negotiation, and leadership (Brown et al., 2006).

As noted, this method is relevant to any cultural context in the world. Other, more cultural knowledge-based approaches depend too heavily on Soldiers' cultural knowledge and cultural interpretation skills. In contrast, our method emphasizes that SPT is an interpersonal activity. The Soldier needs to understand his cultural training is useful in trying to hypothesize about the other person's perspective and behavior, but that he cannot rely on it absolutely. He needs to investigate the perspective of each person with whom he is interacting. He will find he can build positive relationships if he takes the time to find common ground with host nationals. This may be as simple as discovering that each of them has a family or is a father or finding they share a 
common interest of some kind. SPT is greatly served by and can be used to build personal rapport, as it empathically connects two individuals - not because they necessarily think or feel alike, but because they have created common understanding through communication. Thus, the SPT curriculum goes beyond culturally-based generalizations and works on the interpersonal level, taking into account individual differences and personal contexts as well as cultural information.

The curriculum is designed to teach Soldiers what perspective taking is, what benefits it offers them, and how to improve their skills to the point of self-awareness. With time and practice, the new cognitive and behavioral shifts involved can become useful tools for rapport building and, ultimately, mission success. Most Soldiers have the foundational skills they need for social perspective taking, but they need to be willing to engage in SPT. The four step perspective taking method we have outlined here is an effortful process - there must be communication and, whenever possible, verification of a perspective-taking hypothesis. By teaching Soldiers to form and test hypotheses about culturally different others, the SPT method outlined here may take them away from sophisticated stereotyping which may be fraught with error to more accurate social perspective taking.

\section{DISCUSSION}

Social perspective-taking is a skill set enabling a person to understand how another person is reacting to a given situation emotionally and cognitively. In cross-cultural contexts, the ability to accurately take another's perspective can be very difficult as cultural values, beliefs, and biases may differ greatly. The present research is an effort to identify and define the cognitive and behavioral skill sets needed for Soldiers to understand the perspectives - both thoughts and feelings - of other people, especially those from other cultures. The KSAs most helpful for Soldiers learning to improve social perspective taking skills are communication skills, hypothesizing skills, and an awareness of key perceptual biases that lead to incorrect assumptions about the motivations, thoughts, feelings, and behaviors of others. An important goal for today's military personnel is to create relationships with host nationals based on trust and security when possible (Ryan, 2008). Developing this relationship is made possible in part by knowledge of the local culture, but a communication-oriented skill set is of great importance as well.

Though there are many strategies that help Soldiers acquire cultural knowledge and related skills, the best strategies for verifying one's hypothesis about the thoughts and feelings of a person from another culture involve communication. Because most people have a bias in favor of believing that their first hypothesis is likely to be the correct one, it is also important to go beyond that first guess about the perspective of the other person to consider other options, and then to use interpersonal communication to check accuracy.

Through surveys and interviews with Soldiers and SMEs, along with an extensive literature review involving the fields of medicine, psychology, and education, the present effort resulted in a four-step method that will enable Soldiers to gather relevant information, hypothesize about possible perspectives, check in with the other person for more information and confirming or disconfirming evidence, and apply the information gleaned about the other's perspective to the 
goals of the mission at hand. With sufficient practice, the Soldier can achieve automaticity with the four-step method by learning to avoid common perceptual biases (e.g., fundamental attribution error), to create more than one hypothesis about the other person's perspective, and make a habit of checking in whenever possible to see if any of the hypotheses are correct. This is likewise a useful skill set for Army Soldiers who often need to increase trust, understanding, and cooperation or possibly just need to understand what is motivating a host national's behavior. Similarly, host nationals who feel understood by Army Soldiers are likely better able to enter into productive and mutually beneficial relationships with Army personnel. 


\section{References}

Ames, D. R. (2004). Strategies for social inference: A similarity contingency model of projection and stereotyping in attribute prevalence estimates. Journal of Personality and Social Psychology, 8, 573-585.

Artis, S., Keeney, M. J., Beltz, B. M., Reiter-Palmon, R., Brady, T., de Vreede, T., Sageman, M., \& Metcalf, K. A. (under review). The design, development, and evaluation of a military advisor training system (ARI Technical Report). Arlington, VA: U.S. Army Research Institute for the Behavioral and Social Sciences.

Armstrong, D. M. (1961). Perception and the physical world. London: Routledge \& Kegan Paul.

Batson, C. D. (1991). The altruism question: Towards a social-psychological answer. Hillsdale, NJ: Erlbaum.

Batson, C. D., Early, S., \& Salvarani, G. (1995). Immorality from empathy-induced altruism: When compassion and justice conflict. Journal of Personality and Social Psychology, 68, 1042-1054.

Brewer, M. B. (1979). In-group bias in the minimal intergroup situation: A cognitivemotivational analysis. Psychological Bulletin, 86, 307-324.

Brown, J. D., Novick, N. J., Lord, K. A., \& Richards, J. M. (1992). When Gulliver travels: Social context, psychological closeness, and self-appraisals. Journal of Personality and Social Psychology, 62, 717-727.

Brown, S. W., Gehlbach, H., Ioannou, A., Boyer, M. A., Hudson, N., \& Niv-Solomon, A. (2006, May). Motivating social perspective taking in adolescence through heterogeneous groups. Paper presented at the Association for Psychological Science, New York.

Burke, C. S., Hess, K. P., Priest, H. A., Rosen, M., Salas, E., Paley, M., et al. (2005). Facilitating leadership in a global community: a training tool for multicultural team leaders. Paper presented at the Interservice/Industry Training, Simulation, and Education Conference (I/ITSEC), Orlando, FL.

Byram, M. (1997). Teaching and assessing intercultural communicative competence. Bristol, PA: Multilingual Matters, Ltd.

Cacioppo, J. T., \& Petty, R. E. (1982). The need for cognition. Journal of Personality and Social Psychology, 42, 116-131. 
Canli, T., Zhao, Z., Brewer, J., Gabrieli, J. D., \& Cahill, L. (2000). Event-related activation in the human amygdala associates with later memory of individual emotional experience. Journal of Neuroscience, 20, 1-5.

Carter, J. A. (2005). The criterion-based development model for self-instructional training programs. The Behavior Therapist, 28, 48-53.

Caruso, E. M., Epley, N., \& Bazerman, M. H. (2004). The good, the bad, and the ugly of perspective taking in groups. Ethics in Groups: Research on Managing Groups and Teams, 8, 201-224.

Chamberlin, T. C. (n.d.). The method of multiple working hypotheses. Retrieved from http://www.accessexcellence.org/RC/AB/BC/chamberliv.html

Chandler, J. (2005). Why culture matters: an empirically-based pre-deployment training program. Master's thesis, Naval Postgraduate School, Monterey, CA.

Coke, J. S., Batson, C. D., \& McDavis, K. (1978). Empathic mediation of helping: A two-stage model. Journal of Personality and Social Psychology, 36, 752-766.

Corno, L., Cronbach, L. J., Kupermintz, H., Lohman, D. F., Mandinach, E. B., Porteus, A. W., et al. (2002). Remaking the concept of aptitude: extending the legacy of Richard E. Snow. Mahwah, NJ: Erlbaum.

Decety, J. (1995). Perspective taking as the royal avenue to empathy. In B. F. Malle, \& S. D. Hodges (Eds.). Other minds: How humans bridge the divide between self and others. New York: The Guilford Press.

Decety, J., \& Chaminade, T. (2003). When the self represents the other: A new cognitive neuroscience view of psychological identification. Consciousness and Cognition, 12, 577596.

Decety, J., \& Grèzes, J. (2006). The power of simulation: Imagining one’s own and other's behavior. Brain Research, 1079, 4-14.

Decety, J., \& Sommerville, J. A. (2003). Shared representations between self and others: A social cognitive neuroscience view. Trends in Cognitive Science, 7, 527-533.

Derryberry, D., \& Rothbart, M. K. (1988). Arousal, affect, and attention as components of temperament. Journal of Personality and Social Psychology, 55, 958-966.

Deutsch, M. (1993). Educating for a peaceful world. American Psychologist, 48, 510-517.

Devine, P. (1995). Prejudice and out-group perception. In A. Tesser (Ed.), Advanced social Psychology (pp. 466-524). New York: McGraw-Hill. 
Dixon, J. A., \& Moore, C. F. (1990). The development of perspective-taking: Understanding differences in information and weighting. Child Development, 61, 1502-1513.

Dornyei, Z., \& Thurrel, S. (1991). Strategic competence and how to teach it. ELT Journal, 45, 16-23.

Drolet, A., Larrick, R., \& Morris, M. W. (1998). Thinking of others: How perspective taking changes negotiators' aspirations and fairness perceptions as a function of negotiator relationships. Basic and Applied Social Psychology, 20, 23-31.

Earley, P. C. (2004). The elusive cultural chameleon: Cultural intelligence as a new approach to training the global manager. Academy of Management Learning and Education, 3, 110-115.

Earley, P. C., \& Ang, S. (2003). Cultural intelligence: individual interactions across cultures. Stanford: Stanford University Press.

Eccles, J. (1984). Sex differences in achievement patterns. In T. B. Sonderegger (Ed.), Nebraska symposium on motivation (Vol. 32, pp. 97-132). Lincoln: University of Nebraska Press.

Eisenberg, N., Shea, C. L., Carlo, G. \& Knight, G. (1991). Empathy-related responding and cognition: A 'chicken and the egg' dilemma. In W. Kurtines, \& J. Gewirtz (Eds.), Handbook of moral behavior and development (Vol. 1). Hillsdale, NJ: Lawrence Erlbaum Associates.

Elkhamri, M. (2007). Dealing with the Iraqi populace: An Arab-American soldier's perspective. Military Review, 87, 110-113.

Epley, N., Morewedge, C. K., \& Keysar, B. (2004). Perspective taking in children and adults: Equivalent egocentrism but differential correction. Journal of Experimental Social Psychology, 40.

Epley, N., Keysar, B., Van Boven, L., \& Gilovich, T. (2004) Perspective taking as egocentric anchoring and adjustment. Journal of Personality and Social Psychology, 87, 327-339.

Fowler, S. M., \& Mumford, M. G. (Eds.). (1995). Intercultural sourcebook: Cross-cultural training methods (Vol. 1). Boston: Intercultural Press, Inc.

Fowler, S. M. \& Mumford, M. G. (Eds.) (1999). Intercultural sourcebook: Cross-cultural training methods (Vol. 2). Boston: Intercultural Press, Inc.

Frantz, C. M., \& Janoff-Bulman, R. (2000). Considering both sides: The limits of perspective taking. Basic and Applied Social Psychology, 22, 31-42.

Furstenberg. C. T., Carter, J. A., Henderson, J. V., \& Ahles, T. A. (2002). Formative evaluation of a multimedia program for patients about the side effects of cancer treatment. Patient Education and Counseling, 47, 57-62. 
Galinsky, A. D., Ku, G., \& Wang, C. S. (2005). Perspective-taking and self-other overlap: Fostering social bonds and facilitating social cooperation. Group Processes and Intergroup Relations, 8, 109-124.

Galinsky, A. D., Maddux, W. W., \& Ku, G. (2006, March). View from the other side of the table. Negotiation, 3-5.

Galinsky, A. D., \& Moskowitz, G. B. (2000). Perspective-taking: Decreasing stereotype expression, stereotype accessibility, and in-group favoritism. Journal of Personality and Social Psychology, 78, 384-392.

Gehlbach, H. (2004). A new perspective on perspective taking: A multidimensional approach to conceptualizing an aptitude. Educational Psychology Review, 16, 207-236.

Gehlbach, H. (1999). Emotion regulation: Past, present, future. Cognition and Emotion, 13, 551573.

Gehlbach, H., \& Brinkworth, M. E. (2008) Motivated thinkers and the mistakes they make: The goals underlying social cognitions and their consequences for achievement. In Maehr, M. L., Karabenick, S. \& Urdan, T. (Eds.), Advances in motivation and achievement: social psychological perspective on motivation and achievement (Vol. 15). Philadelphia: Elsevier.

Gilbert, D. T., \& Malone, P. S. (1995). The correspondence bias. Psychological Bulletin, 117, 21-38.

Gillespie, A. (2006). Games and the development of perspective taking. Human Development, 49, 87-92.

Gilligan, C. (1982). In a different voice. Cambridge: Harvard University Press.

Grandey, A., Fisk, G. M., \& Steiner, D. D. (2005). Must 'service with a smile’ be stressful? The moderating role of personal control for U.S. and French employees. Journal of Applied Psychology, 90, 893-914.

Griffin, D. W., Dunning, D., \& Ross, L. (1990). The role of construal processes in overconfident predictions about the self and others. Journal of Personality and Social Psychology, 59, 1128-1139.

Gross, J. G. (1998). The emerging field of emotion regulation: an integrative review. Review of General Psychology, 2, 271-299.

Gross, J. G. (1999). Emotion regulation: past, present, future. Cognition and Emotion, 13, 551573.

Gross, J. G. (Ed.). (2006). Handbook of emotion regulation. New York: The Guilford Press. 
Gross, J. G., \& Munoz, R.F. (1995) Emotion regulation and mental health. Clinical Psychology : Science and Practice, 2, 151-164.

Hall, E. T. (1959). The Silent Language. New York: Doubleday \& Co.

Halpern, J. (2001). From detached concern to empathy: humanizing medical practice. New York: Oxford University Press.

Hardee, J. T. (2003). An overview of empathy. The Permanente Journal, 7. Retrieved from http://xnet.kp.org/permanentejournal/fallo3/cpc.html

Hardee, J. T., \& Kasper, I. K. (2005). From standardized patient to care actor: evolution of a teaching methodology. The Permanente Journal, 9. Retrieved from http://xnet.kp.org/permanentejournal/sum05/actor.html

Hartley, C., \& Hopkins, R. S. (1999). Developing a dual perspective. In S. M. Fowler \& M. G. Mumford (Eds.), Intercultural sourcebook: Cross-cultural training methods (Vol. 2). Boston: Intercultural Press, Inc.

Hacher, S. L., Nadeau, M. S., Walsh, L. K., Reynolds, M., Galea, J., \& Marz, K. (1994). The teaching of empathy for high school and college students: testing Rogerian methods with the interpersonal reactivity index. Adolescence, Winter.

Hayes, S. C., Barnes-Holmes, D., \& Roche, B. (Eds.). (2001). Relational frame theory: A PostSkinnerian account of human language and cognition. New York: Plenum Press.

Hoffman, M. (1977). Empathy, its development and prosocial implications. In C. B. Keasey (Ed.), Nebraska Symposium on Motivation: Vol. 25. Lincoln: University of Nebraska Press.

Hoffman, M. (2000). Empathy and moral development: implications for caring and justice. New York: Cambridge University Press.

Hofstede, G. (1980). Culture's consequences: International differences in work-related values. Beverly Hills: Sage.

Hofstede, G. (2001). Culture's consequences: Comparing values, behaviors, institutions, and organizations across nations (2nd ed.). Thousand Oaks, CA: Sage.

Hoopes, D. S. (1979). Intercultural communication experience. In M.D. Pusch (Ed.), Multicultural education: A cross-cultural training approach (pp. 9-42). Yarmouth, ME: Intercultural Press.

Howard, K. W. (1989). A comprehensive expectancy motivation model: Implications for adult education and training. Adult Education Quarterly, 39, 199-210.

Ickes, W. J. (Ed.). (1997). Empathic accuracy. New York: The Guilford Press. 
Ickes, W. J., Stinson, L., Bissonnette, V., \& Garcia, S. (1990). Naturalistic social cognition: Empathic accuracy in mixed-sex dyads. Journal of Personality and Social Psychology, 59, 730-742.

Jackson, P., \& Decety, J. (2004). Motor cognition: A new paradigm to study self-other interactions. Current Opinion in Neurobiology, 14, 259-263.

Jandt, F. E. (2001). Intercultural communication ( $3^{\text {rd }}$ ed.). Thousand Oaks: Sage Publications, Inc.

Jennings, D. (1996). Strategic management and the case method. Journal of Management Development, 15, 4-12.

Johnson, D. W. (1975). Cooperativeness and social perspective taking. Journal of Personality and Social Psychology, 31, 241-244.

Kawada, C., Oettingen, G., Gollwitzer, P., \& Bargh, J. (2004) The projection of implicit and explicit goals. Journal of Personality and Social Psychology, 86, 545-559.

Keysar, B., Lin, S., \& Barr, D. J. (2003). Limits on theory of mind use in adults. Cognition, 89, 25-41.

Klein, H. A. (2004). Cognition in natural settings: The cultural lens model. In M. Kaplan (Ed.), Cultural ergonomics: advances in human performance engineering research (Vol. 4, pp. 249-280). Philadelphia: Elsevier.

Kohlberg, L. (1969). Stage and sequence: The cognitive-developmental approach to socialization. In D. A. Goslin (Ed.), Handbook of socialization theory and research. Chicago: Rand McNally.

Kunda, Z., Davies, P. G., Adams, B. D., \& Spencer, S. J. (2002). The dynamic time course of stereotype activation: Activation, dissipation, and resurrection. Journal of Personality and Social Psychology, 82, 283-299.

Lacy, L., \& Trowbridge, J. (1995). Using the case study as a training tool. In. S. M. Fowler \& M. G. Mumford (Eds.), Intercultural sourcebook: Cross-cultural training methods (Vol. 1). Boston: Intercultural Press.

Le Roux, J. (2002). Effective educators are culturally competent communicators. Intercultural Education, 13, 37-49.

Levinson, W., Gorawara-Bhat, R., \& Lamb, J. (2000). A study of patient clues and physician responses in primary care and surgical settings. Journal of the American Medical Association, 284, 1021-1027. 
Lewis, B. G., Lt. Col. (2006). Developing soldier cultural competency. Strategy Research Project. Carlisle Barracks, PA: U. S. Army War College.

Malle, B. F., \& Hodges, S. D. (Eds.). (2005). Other minds: How humans bridge the divide between self and others. New York: The Guilford Press.

Markus, H. R., \& Kitayama, S. (1994). The cultural construction of self and emotion: Implications for social behavior. In S. Kitayama and H. R. Markus (Ed.), Emotion and Culture. Baltimore: United Book Press.

Masellis, N. (2009). Human terrain: A strategic imperative on the $21^{\text {st }}$ century battlefield. Small Wars Journal. Retrieved from http://smallwarsjournal.com/blog/journal/docs-temp/250marsellis.pdf

Matsumoto, D. M. (2004). Paul Ekman and the legacy of universals. Journal of Research in Personality, 38, 45-51.

Matsumoto, D. M., \& Juang, L. (Eds.). (2004). Culture and psychology (4 ${ }^{\text {th }}$ ed.). Belmont, CA: Thomson Wadsworth.

Matsumoto, D. M., Le Roux, J. A., Bernhard, R., Gray, H. (2004). Unraveling the psychological correlates of intercultural adjustment potential. Intercultural Journal of Intercultural Relations, 28, 281-309.

Matsumoto, D. M., \& Le Roux, J. A. (2003). Measuring the psychological engine of intercultural adjustment: The Intercultural Adjustment Potential Scale (ICAPS). Journal of Intercultural Communication, 6, 37-52.

Matsumoto, D. M., Yoo, S. H., \& Le Roux, J. A. (2007). Emotion and intercultural communication. In H. Kotthoff, \& H. Spencer-Oatley (Eds.), Handbook of applied linguistics (Vol. 7). New York: Mouton de Gruyter Publishers.

Mauss, I. B., Bunge, S. A., \& Gross, J. J. (2007) Automatic emotion regulation. Social and Personality Psychology Compass, 1. Retrieved from http://www.du.edu/psychology/erl/sppc_AER.pdf.

McCaffery, J. A. (1995). The role play: A powerful but difficult training tool. In S. M. Fowler \& M. G. Mumford (Eds.), Intercultural sourcebook: Cross-cultural training methods (Vol. 1). Boston: Intercultural Press.

McCraig, N. M. (1999). The Malonarian cultural expedition team: Exploring behavioral reflections on mainstream U.S. values. In S. M. Fowler \& M. G. Mumford (Eds.), Intercultural sourcebook: Cross-cultural training methods (Vol. 2). Boston: Intercultural Press, Inc. 
Mehrabian, A., \& Ferris, S. (1967). Inference of attitudes from nonverbal communication in two channels. Journal of Consulting Psychology, 31, 248-252.

Mendoza, R. (1997). Emotional versus situational inductions of empathy: effects on interpersonal understanding and punitiveness. Unpublished doctoral dissertation, Stanford University.

Metcalf, K. A. \& Zbylut, M. L. (2007). Army Excellence in Leadership (AXL): Educating Army leaders with the Tripwire film. (ARI Research Product 2007-03). Arlington, VA: US Army Research Institute for the Behavioral and Social Sciences.

Miller, D. T., \& Prentice, D. A. (1994). The self and the collective. Personality and Social Psychology Bulletin, 20, 451-453.

Odom, T. P. (2007). America's cultural first battles: Understanding the influence of culture on war. Small Wars Journal Magazine, 9. 21-29. Retrieved from http://smallwarsjournal.com/documents/swjvol9.pdf

Osland, J., \& Bird, A. (2003). Beyond sophisticated stereotyping: Cultural sense-making in context. In D. C. Thomas (Ed.), Reading and cases in international management: a crosscultural perspective. Sage: Thousand Oaks.

Pelias, R. J. (1984). Oral interpretation as a training method for increasing perspective taking abilities. Communication Education, 33, 143-151.

Piaget, J. (1924.) Judgment and reasoning in the child. Totowa, NJ: Littlefield, Adams.

Pusch, M. D. (1979). Multicultural education: A cross cultural training approach. La Grange Park, IL: Intercultural Network, Inc.

Reeder, G. D., \& Trafimow, D. (2005). Attributing motives to other people. In B. F. Malle, \& S. D. Hodges (Eds.). Other minds: How humans bridge the divide between self and others. New York: The Guilford Press.

Richardson, D. R., Green, L. R., \& Lago, T. (1998). The relationship between perspectivetaking and nonaggressive responding in the face of an attack. Journal of Personality, 66, 235-256.

Rippin, A., Booth, C., Bowie, S., \& Jordan, J. (2002). A complex case: Using the case study method to explore uncertainty and ambiguity in undergraduate business education. Teaching in Higher Education, 7, 429-441.

Roeser, R. W., Eccles, J. S., \& Strobel, K. R. (1998). Linking the study of schooling and mental health: Selected issues and empirical illustrations at the level of the individual. Journal of Educational Psychology, 33, 153-176. 
Rokeach, M. (1960). The open and closed mind: Investigations into the nature of belief systems and personality systems. New York: Basic Books.

Rosenbaum, M.E., \& Holtz, R. (1985). The minimal intergroup discrimination effect: Out-group derogation, not in-group favoritism. Paper presented at the $93^{\text {rd }}$ annual convention of the American Psychological Association, Los Angeles.

Ross, L. (1977). The intuitive psychologist and his shortcomings: Distortions in the attribution process. In L. Berkowitz (Ed.), Advances in Experimental Social Psychology (Vol. 10). New York: Academic Press.

Ross, L., \& Ward, A. (1995, May). Naïve realism: Implications for social conflict and misunderstanding. Working Paper No. 48. Stanford Center on Conflict and Negotiation. Stanford, CA.

Rossing, B. E., \& Long, H. B. (1981). Contributions of curiosity and relevance to adult learning motivation. Adult Education Quarterly, 32, 25-36.

Ruby, P., \& Decety, J. (2004). How would you feel versus how do you think she would feel? A neuroimaging study of perspective-taking with social emotions. Journal of Cognitive Neuroscience, 16, 988-999.

Ryan, S. (2008). Being an advisor: What you always wanted to know! Air Land Sea Bulletin, 2008-2, 12-15.

Selman, R. L. (1971). The relation of role taking in the development of moral judgment in children. Child Development, 42, 78-91.

Selman, R. L., \& Byrne, D. F. (1974). A structural developmental analysis of levels of role taking in middle childhood. Child Development, 45, 803-806.

Snow, R. E. (1996). Aptitude development and education. Psychology, Public Policy, and Law, 2, 536-560.

Stewart, E. C., \& Bennett, M. J. (1991). American cultural patterns: A cross-cultural perspective. Intercultural Press, Inc.

Storti, C. (1999). Cross-cultural dialogues. In S. M. Fowler \& M. G. Mumford (Eds.), Intercultural sourcebook: Cross-cultural training methods (Vol. 2). Boston: Intercultural Press, Inc.

Tajfel, H. (1970). Experiments in intergroup discrimination. Scientific American, 223, 96-102.

Triandis, H. C. (1995). Culture-specific assimilators. In S. M. Fowler \& M. G. Mumford (Eds.), Intercultural sourcebook: Cross-cultural training methods (Vol. 1). Boston: Intercultural Press. 
U.S. Department of the Army (2006a). Army leadership: Competent, confident and agile (FM 622). Washington, DC: Author.

U.S. Department of the Army (2006b). Counterinsurgency (FM 3-24). Washington, DC: Author.

U.S. Department of the Army (2008). Training in full spectrum operations (FM 7-0). Washington, DC: Author.

U.S. Department of the Army (2009). Tactics in counterinsurgency (FM3-24.2). Washington, DC: Author.

Van Boven, L., \& Loewenstein, G. (2003). Projection of transient drive states. Personality and Social Psychology Bulletin, 29, 1159-1168.

Van Boven, L., \& Loewenstein, G. (2005). Empathy gaps in emotional perspective taking. In B. F. Malle, \& S. D. Hodges (Eds.). Other minds: How humans bridge the divide between self and others. New York: The Guilford Press.

Vescio, T. K., Sechrist, G. B., \& Paolucci, M. P. (2003). Perspective taking and prejudice reduction: The mediational role of empathy arousal and situational attributions. European Journal of Social Psychology, 33, 455-472.

Wason, P. C. (1960). On the failure to eliminate hypotheses in a conceptual task. The Quarterly Journal of Experimental Psychology, 12, 129-140.

Wight, A. R. (1995). The critical incident as a training tool. In S. M. Fowler \& M. G. Mumford (Eds.), Intercultural sourcebook: Cross-cultural training methods (Vol. 1). Boston: Intercultural Press.

Wilmer, H. A. (1968). The doctor-patient relationship and issues of pity, sympathy and empathy. British Journal of Medical Psychology, 41, 243-8.

Winner, M. (n.d.) Perspective taking across the school and adult years for persons with social cognitive deficits. Retrieved from http://www.socialthinking.com/idb/documents/About\%20The\%20PerspectiveTaking\%20Spectrum,\%2011-03.doc

Yayang, F. (1993). Listening: problems and solutions. Forum, 31, 16-21.

Zbylut, M. L., Brunner, J. M., Vowels, C. L., \& Kim, J. M. (2007). Case method instruction: 25 minutes of discussion can make a difference. (ARI Technical Report 1203). Arlington, VA: US Army Research Institute for the Behavioral and Social Sciences. 
Appendix A

\section{Full Set of 41 Perspective Taking KSAs: Organized by Content and Format (K,S, or A)}

\section{Interacting with others}

1. Knowledge

a. Basic knowledge of in-group and out-group dynamics (in-group is any group the soldier belongs to like family or troupe while out-group is any group of which he is not a member

b. Understands other factors and biases that that influence perceptions of self and others (for instance, tendency for people involved in a situation to view things differently from people not involved in the situation

2. Skills

c. Understands the difference between empathy, sympathy, and pity

a. Uses social mimicry (mimics things like dress, eating habits, body language) skillfully to reinforce perspective taking response to persons in another culture

b. Communicates empathy towards a person from another culture

c. Anticipates areas of potential conflict based on thinking differences

d. Uses people-observing skills

\section{Communication}

1. Knowledge

a. Understands that hearing and listening are not the same

2. $\underline{\text { Skills }}$

a. Uses question asking skills

b. Checks for understanding in a cross-cultural exchange

c. Listens for understanding

d. Uses nonverbal communication skills

e. Increases positive attitudes toward people of other cultures

\section{Foreign cultures}

1. Knowledge

a. Understands the universal values, beliefs, and attitudes that all cultures share

b. Understands that some judgments the soldier makes about host nationals and vice versa have their basis in general cultural differences

\section{Self-awareness}

1. Knowledge

a. Knows own ability in social perspective taking

b. Understands American military culture's cognitive biases

c. Understands American culture cognitive biases (cog biases are differences in ways cultures think about things like time, power, relationships, criticism, etc.)

d. Understands self and how he or she relates to in-groups and out-groups

e. Understands how host nationals may perceive the Soldier based on cultural differences and stereotypes 


\section{Self-awareness (cont.)}

2. Skills

a. Assesses self-identity through the perspective of personal experience and background

b. Assesses self through the perspective of common American culture

c. Assesses self through perspective of American military culture

d. Increases awareness of his or her own cultural values and unstated cultural assumptions

\section{Self-regulation}

1. Skills

a. Alters behavior based on taking others' perspective

b. Regulates own emotions before, during, and after stressful cultural exchanges

c. Asks questions to check interpretation before making decisions about next steps

\section{Open-mindedness}

1. Knowledge

a. Understands the notion that one culture is not better than another

b. Understands that a behavior can be interpreted differently based on culture

c. Understands the differences in thinking about men and women's roles in different cultures

d. Understands differences in thinking based on religion

2. Skills

a. Tolerates uncertainty and postpones judgment

b. Increases openness to other cultures

3. Abilities

a. Ability to take perspective of in-group as well as out-group other

b. Motivational desire for perspective taking

\section{The perspective taking process}

1. Knowledge

a. Understands the concept of social perspective taking

b. Understands the relevance of social perspective taking to military mission success

c. Understands consequences of faulty perspective taking

d. Understands the concept of cultural cognitive biases and their importance to effective perspective taking

e. Knows the difference between an observation about another's behavior and an interpretation of another's behavior

f. Knows pitfalls of stereotypes and prejudices towards people of other cultures and how they can lead to faulty social perspective taking 


\section{Appendix B}

\section{Cross-Cultural Social Perspective Taking Survey}

Because of your expertise in cross-cultural exchanges for the military, you have been chosen to participate in this survey. We very much value your work and would appreciate your input. We would be happy to write a thank-you letter to your superior officer regarding your helpfulness in this effort if you desire.

The purpose of this questionnaire is to determine what knowledge, skills, and attitudes (KSAs) are most important for a Soldier stationed overseas to possess for effectively taking the perspective of a person from his or her host country. We've been asked to design a curriculum to teach Soldiers perspective taking, which we define as the ability to put oneself in the place of another while recognizing that the other person may have thoughts and feelings different from one's own. The results of this survey will help focus on specific KSAs for overseas deployments.

Please take approximately 10 minutes to fill out the following survey and return it to us at lroan@ecrossculture.com. This effort has been funded by the U.S. Army Research Institute for the Behavioral and Social Sciences (ARI) under a Small Business Innovation Research initiative.

Please hit 'reply' before beginning.

\section{Questionnaire}

The following knowledge, skills, and attitudes have been identified in the literature or in our conversations with psychologists and cultural anthropologists as the abilities needed to effectively take the perspective of another person, particularly in cross-cultural exchanges.

Each question requires a number from 1 to 3 indicating your opinion on the importance of the perspective taking characteristic. The scale is shown below.

\section{Scale}

$1=$ Essential

2=Important

3=Unimportant

Please limit your \#1 responses (essential) to no more than twenty as we want to identify key KSAs.

If you have a comment about a particular question, please enter it on the line immediately beneath the question. 
Prerequisite, Primary and Secondary Skills for learning social perspective taking.

Assign a number to the following KSAs:

What do you think a Soldier needs to be an effective cross-cultural perspective taker?

Question 1: People-observing skills:

Question 2: Nonverbal communication skills:

Question 3: Understands that hearing and listening are not the same:

Question 4: Listens for understanding:

Question 5: Checks for understanding in a cross-cultural exchange:

Question 6: Question asking skills:

Question 7: Motivational desire for perspective taking:

Question 8: Regulates own emotions before, during, and after stressful cultural exchanges:

Question 9: Assesses self-identity through the perspective of personal experience and background:

Question 10: Assesses self through the perspective of common American culture:

Question 11: Assesses self through perspective of American military culture:

Question 12: Increases awareness of his or her own cultural values and unstated cultural assumptions:

Question 13: Understands the concept of social perspective taking:

Question 14: Understands the relevance of social perspective taking to military mission success:

Question 15: Knows own ability in social perspective taking:

Question 16: Understands the difference between empathy, sympathy, and pity:

Question 17: Understands American culture cognitive biases (cognitive biases are differences in ways cultures think about things like time, power, relationships, criticism, etc.):

Question 18: Understands American military culture's cognitive biases: 
Question 19: Basic knowledge of in-group and out-group dynamics (in-group is any group the Soldier belongs to like family or troupe while out-group is any group of which he is not a member):

Question 20: Understands self and how he or she relates to in-groups and out-groups:

Question 21: Ability to take perspective of in-group as well as out-group other:

Question 22: Knows the difference between an observation about another's behavior and an interpretation of another's behavior:

Question 23: Understands consequences of faulty perspective taking:

Question 24: Asks questions to check interpretation before making decisions about next steps:

Question 25: Tolerates uncertainty and postpones judgment:

Question 26: Increases positive attitudes toward people of other cultures:

Question 27: Increases openness to other cultures:

Question 28: Understands the notion that one culture is not better than another:

Question 29: Understands that some judgments the Soldier makes about host nationals and vice versa have their basis in general cultural differences:

Question 30: Understands that a behavior can be interpreted differently based on culture:

Question 31: Understands the universal values, beliefs, and attitudes that all cultures share:

Question 32: Understands concept of cultural cognitive biases and their importance to effective perspective taking:

Question 33: Understands the differences in thinking about men and women's roles in different cultures:

Question 34: Understands differences in thinking based on religion:

Question 35: Anticipates areas of potential conflict based on thinking differences:

Question 36: Alters behavior based on taking others’ perspective:

Question 37: Knows pitfalls of stereotypes and prejudices towards people of other cultures and how they can lead to faulty social perspective taking: 
Question 38: Understands other factors and biases that influence perceptions of self and others (for instance, fundamental attribution error, naïve realism, and confirmation bias):

Question 39: Understands how host nationals may perceive the Soldier based on cultural differences and stereotypes:

Question 40: Communicates empathy towards a person from another culture:

Question 41: Uses social mimicry (mimics things like dress, eating habits, body language) skillfully to reinforce perspective taking response to persons in another culture:

\section{$\underline{\text { Non-numeric responses }}$}

Question 1: Of the aforementioned KSAs, which do you think is the most important for the Soldier to possess and why?

Question 2: Of the aforementioned KSAs, which do you think is the least important for the Soldier to possess and why?

Question 3: Are there any relevant KSAs missing?

Question 4: What advice or suggestions do you have for us in planning cross-cultural perspective taking curriculum? What do you think Soldiers respond best to in training (video, role plays, lecture, computer simulations...)? Were you trained in social perspective taking?

Question 5: Is there anyone you know that might be helpful for us to talk with or fill out this survey? What is their contact information?

Question 5: May we contact you for a phone interview?

Please indicate if you would like to remain anonymous.

Thank you, Linda Roan, President

eCrossCulture Corporation 
Appendix C

\section{Survey Results of SPT Academic SMEs and Soldiers}

Following are two tables presenting results from surveys sent to SPT researchers (Table C-1) and Soldiers (Table C-2). Each of the SPT researchers and Soldiers were asked to indicate whether each of the 41 skills was 1) essential, 2) important, or 3) unimportant to perspective taking. All of the responses for the SPT researchers and Soldiers are presented individually below. Followup interviews were conducted with all SPT researchers and Soldier survey respondents.

Table C-1

SPT Academic SMEs’ Survey Responses

\begin{tabular}{|l|l|l|l|l|l|l|l|}
\hline & & \multicolumn{5}{|c|}{ Importance Ratings from } \\
\hline & Perspective Taking Skill & 1 & 2 & 3 & 4 & 5 & 6 \\
\hline & & & & & & & \\
\hline 1 & People-observing skills & 2 & 2 & 1 & 1 & 1 & 1 \\
\hline 2 & Nonverbal communication skills & 1 & 1 & 2 & 2 & 1 & 1 \\
\hline 3 & Understands that hearing and listening are not the same & 2 & 2 & 2 & 1 & 2 & 2 \\
\hline 4 & Listens for understanding & 2 & 1 & 2 & 1 & 2 & 2 \\
\hline 5 & Checks for understanding in a cross-cultural exchange & 2 & 2 & 1 & 1 & 1 & 1 \\
\hline 6 & Question asking skills & 3 & 2 & 1 & 1 & 2 & 2 \\
\hline 7 & Motivational desire for perspective taking & 2 & 3 & 2 & 2 & 2 & 2 \\
\hline 8 & $\begin{array}{l}\text { Regulates own emotions before, during, and after stressful } \\
\text { cultural exchanges }\end{array}$ & 1 & 2 & 1 & 2 & 1 & 1 \\
\hline 9 & $\begin{array}{l}\text { Assesses self-identity through the perspective of personal } \\
\text { experience and background }\end{array}$ & 2 & 2 & 1 & 2 & 2 & 2 \\
\hline 10 & $\begin{array}{l}\text { Assesses self through the perspective of common } \\
\text { American culture }\end{array}$ & 2 & 2 & 2 & 2 & 3 & 2 \\
\hline 11 & $\begin{array}{l}\text { Assesses self through perspective of American military } \\
\text { culture }\end{array}$ & 2 & 2 & 3 & 2 & 3 & 2 \\
\hline 12 & $\begin{array}{l}\text { Increases awareness of his or her own cultural values and } \\
\text { unstated cultural assumptions }\end{array}$ & 2 & 2 & 3 & 1 & 2 & 1 \\
\hline 13 & Understands the concept of social perspective taking & 3 & 1 & 1 & 2 & 2 & 1 \\
\hline 14 & $\begin{array}{l}\text { Understands the relevance of social perspective taking to } \\
\text { military mission success }\end{array}$ & 2 & 1 & 2 & 2 & 1 & 2 \\
\hline 15 & Knows own ability in social perspective taking & 1 & 2 & 1 & 2 & 2 & 2 \\
\hline 16 & $\begin{array}{l}\text { Understands the difference between empathy, sympathy, } \\
\text { and pity }\end{array}$ & 1 & 2 & 1 & 2 & 2 & 2 \\
\hline 17 & $\begin{array}{l}\text { Understands American culture cognitive biases (cog biases } \\
\text { are differences in ways cultures think about things like } \\
\text { time, power, relationships, criticism, etc.): }\end{array}$ & 2 & 2 & 2 & 2 & 3 & 3 \\
\hline 18 & Understands American military culture's cognitive biases & 2 & 2 & 1 & 2 & 3 & 2 \\
\hline & & & & & \\
\hline
\end{tabular}




\begin{tabular}{|c|c|c|c|c|c|c|c|}
\hline 19 & $\begin{array}{l}\text { Basic knowledge of in-group and out-group dynamics (in- } \\
\text { group is any group the soldier belongs to like family or } \\
\text { troupe while out-group is any group of which he is not a } \\
\text { member) }\end{array}$ & 2 & 3 & 2 & 2 & 2 & 2 \\
\hline 20 & $\begin{array}{l}\text { Understands self and how he or she relates to in-groups } \\
\text { and out-groups }\end{array}$ & 2 & 3 & 2 & 2 & 2 & 3 \\
\hline 21 & $\begin{array}{l}\text { Ability to take perspective of in-group as well as out-group } \\
\text { other }\end{array}$ & 1 & 3 & 2 & 2 & 2 & 2 \\
\hline 22 & $\begin{array}{l}\text { Knows the difference between an observation about } \\
\text { another's behavior and an interpretation of another's } \\
\text { behavior }\end{array}$ & 2 & 2 & 2 & 1 & 1 & 1 \\
\hline 23 & Understands consequences of faulty perspective taking & 2 & 1 & 2 & 1 & 1 & 1 \\
\hline 24 & $\begin{array}{l}\text { Asks questions to check interpretation before making } \\
\text { decisions about next steps }\end{array}$ & 2 & 1 & 1 & 1 & 1 & 1 \\
\hline 25 & Tolerates uncertainty and postpones judgment & 2 & 2 & 2 & 1 & 1 & 1 \\
\hline 26 & Increases positive attitudes toward people of other cultures & 2 & 2 & 1 & 2 & 2 & 2 \\
\hline 27 & Increases openness to other cultures & 2 & 2 & 1 & 1 & 1 & 2 \\
\hline 28 & $\begin{array}{l}\begin{array}{l}\text { Understands the notion that one culture is not better than } \\
\text { another }\end{array}\end{array}$ & 1 & 2 & 1 & 2 & 2 & 2 \\
\hline 29 & $\begin{array}{l}\text { Understands that some judgments the soldier makes about } \\
\text { host nationals and vice versa have their basis in general } \\
\text { cultural differences }\end{array}$ & 1 & 1 & 2 & 1 & 1 & 1 \\
\hline 30 & $\begin{array}{l}\text { Understands that a behavior can be interpreted differently } \\
\text { based on culture }\end{array}$ & 1 & 1 & 1 & 1 & 1 & 1 \\
\hline 31 & $\begin{array}{l}\text { Understands the universal values, beliefs, and attitudes that } \\
\text { all cultures share }\end{array}$ & 2 & 2 & 3 & 1 & 2 & 2 \\
\hline 32 & $\begin{array}{l}\text { Understands concept of cultural cognitive biases and their } \\
\text { importance to effective perspective taking }\end{array}$ & 1 & 2 & 2 & 2 & 1 & 1 \\
\hline 33 & $\begin{array}{l}\text { Understands difference in thinking about men and women's } \\
\text { roles in different cultures }\end{array}$ & 2 & 1 & 2 & 2 & 1 & 2 \\
\hline 34 & Understands differences in thinking based on religion & 2 & 1 & 2 & 2 & 1 & 2 \\
\hline 35 & $\begin{array}{l}\text { Anticipates areas of potential conflict based on thinking } \\
\text { differences }\end{array}$ & 2 & 2 & 1 & 2 & 1 & 1 \\
\hline 36 & Alters behavior based on taking others' perspective & 2 & 1 & 1 & 1 & 1 & 1 \\
\hline 37 & $\begin{array}{l}\text { Knows pitfalls of stereotypes and prejudices towards } \\
\text { people of other cultures and how they can lead to faulty } \\
\text { social perspective taking }\end{array}$ & 1 & 2 & 2 & 2 & 1 & 2 \\
\hline 38 & $\begin{array}{l}\text { Understands other factors and biases that influence } \\
\text { perceptions of self and others (for instance, tendency for } \\
\text { people involved in a situation to view things differently } \\
\text { from people not involved in the situation): }\end{array}$ & 2 & 2 & 2 & 2 & 2 & 2 \\
\hline 39 & $\begin{array}{l}\text { Understands how host national may perceive the soldier } \\
\text { based on cultural differences and stereotypes }\end{array}$ & 2 & 1 & 2 & 2 & 1 & 1 \\
\hline 40 & $\begin{array}{l}\text { Communicates empathy towards a person from another } \\
\text { culture }\end{array}$ & 2 & 2 & 2 & 2 & 2 & 3 \\
\hline
\end{tabular}




\begin{tabular}{|l|l|l|l|l|l|l|l|}
\hline 41 & $\begin{array}{l}\text { Uses social mimicry (mimics things like dress, eating } \\
\text { habits, body language) skillfully to reinforce perspective } \\
\text { taking response to persons in another culture }\end{array}$ & 1 & 1 & 2 & 3 & 1 & 2 \\
\hline
\end{tabular}

\section{SPT Academic SMEs’ Responses to Open-Ended Questions}

Question 1: Of the aforementioned KSAs, which do you think is the most important for the Soldier to possess and why?

Subject $1 \quad$ Understand non-verbal behavior.

Subject 2 While all of the KSA are important, \#29 seems particularly critical. Judgments a soldier makes about host nationals (and vice versa) are often based on cultural differences and biases based thinking. Clearly, generalizations and stereotypes can influence our actions and decisions.

Subject 3 . We are very isolated culturally and socially in the U.S. So we often forget (or don't even know) that we have biases.

Subject $4 \quad \# 5$ because understanding is embedded in social perspective taking if we are to be effective.

Subject 5 Understands the relevance of cultural perspective taking to military mission success." In this specific case, I think motivation is necessary for PT to be successful. Tying perspective taking to the end goal of mission success is therefore a vital aspect to encourage perspective taking.

Question 2: Of the aforementioned KSAs, which do you think is the least important for the Soldier to possess and why?

Subject 1 Understand conceptual issues. This is important for researchers and academics.

Subject 2 All of the above are important and interlinked in some way. \#7 is a bit ambiguous (motivational desire for perspective taking).

Subject $3 \quad 31$ - I'm not entirely sure that there really are "universal” values and beliefs.

Subject $4 \quad \# 40$ because communicating empathy may be very difficult to do in a completely honest manner without appearing to be motivated to manipulate the situation tough to do and unlikely to be successful.

Subject $5 \quad$ Assesses self through the lens of common American cultural perspective." I think more important is to being able to assess self through the lens of the other group.

Question 3: Are there any relevant KSAs missing?

Subject 2 Your list is extensive and quite inclusive. A concept that I did not see explicitly highlighted is Goleman's "Emotional Intelligence". This concept is certainly incorporated in your KSAs, but perhaps not specifically. Goleman's good book on the subject focuses on the ability to understand another person from within their frame of reference. He discusses things like "people skills", "empathy", "leadership" and "listening, influencing, motivating, and collaborating" thru the 
lens of better understanding people. All of the above are important and interlinked in some way. \#7 is a bit ambiguous (motivational desire for perspective taking).

Subject 4 A colleague and I have been doing this type of work for 10 years with students in middle school and high school environments using a simulation on international negotiations, www.globaled.uconn.edu It has been very successful.

Subject 5 Be aware of the specific stereotypes of the host country.

Question 4: What advice or suggestions do you have for us in planning cross-cultural perspective taking curriculum? Any resources you think we should be aware of?

Subject 2 I'm a physician and am involved in teaching communication skills to other physicians and healthcare providers. Over the years, one of the most important things we've discovered in teaching this sort of curriculum is: setting the context. That is, providing the learner a context for how and why this information is important. Communication training can be somewhat esoteric and difficult for some people to grasp conceptually. We note that communication skills are tools....and at different times, different tools are needed. For physicians, just as a scalpel is a tool to accomplish an objective, communication skills are also important tools to have available. Another thing we've found useful in teaching communication skills is to have the learners have the ability to practice the skills. We teach things like empathic communication, and then utilize actors (standardized patients) to then allow the learners to try out the skills which we've discussed. This takes esoteric concepts and makes them real. We devise different scenarios and allow for "real-time" practice and feedback. This gives the learner confidence and helps cement the learnings. Understand non-verbal behavior. 
Table C-2

Soldier Survey Responses

\begin{tabular}{|c|c|c|c|c|c|}
\hline & \multirow[t]{2}{*}{ Perspective Taking Skill } & \multicolumn{4}{|c|}{$\begin{array}{l}\text { Importance Ratings } \\
\text { from Soldiers 1-4 }\end{array}$} \\
\hline & & 1 & 2 & 3 & 4 \\
\hline 1 & People-observing skills & 2 & 1 & 2 & 1 \\
\hline 2 & Nonverbal communication skills & 1 & 1 & 1 & 1 \\
\hline 3 & Understands that hearing and listening are not the same & 3 & 2 & 2 & 3 \\
\hline 4 & Listens for understanding & 2 & 2 & 3 & 2 \\
\hline 5 & Checks for understanding in a cross-cultural exchange & 1 & 2 & 2 & 1 \\
\hline 6 & Question asking skills & 2 & 1 & 2 & 1 \\
\hline 7 & Motivational desire for perspective taking & 3 & 2 & 3 & 2 \\
\hline 8 & $\begin{array}{l}\text { Regulates own emotions before, during, and after stressful } \\
\text { cultural exchanges }\end{array}$ & 2 & 2 & 2 & 3 \\
\hline 9 & $\begin{array}{l}\text { Assesses self-identity through the perspective of personal } \\
\text { experience and background }\end{array}$ & 2 & 2 & 2 & 2 \\
\hline 10 & $\begin{array}{l}\text { Assesses self through the perspective of common American } \\
\text { culture }\end{array}$ & 2 & 3 & 3 & 3 \\
\hline 11 & Assesses self through perspective of American military culture & 1 & 3 & 2 & 1 \\
\hline 12 & $\begin{array}{l}\text { Increases awareness of his or her own cultural values and } \\
\text { unstated cultural assumptions }\end{array}$ & 2 & 2 & 3 & 2 \\
\hline 13 & Understands the concept of social perspective taking & 2 & 2 & 3 & 3 \\
\hline 14 & $\begin{array}{l}\text { Understands the relevance of social perspective taking to } \\
\text { military mission success }\end{array}$ & 2 & 2 & 3 & 3 \\
\hline 15 & Knows own ability in social perspective taking & 2 & 3 & 3 & 3 \\
\hline 16 & $\begin{array}{l}\text { Understands the difference between empathy, sympathy, and } \\
\text { pity }\end{array}$ & 1 & 3 & 3 & 3 \\
\hline 17 & $\begin{array}{l}\text { Understands American culture cognitive biases (cog biases are } \\
\text { differences in ways cultures think about things like time, power, } \\
\text { relationships, criticism, etc.): }\end{array}$ & 1 & 3 & 2 & 3 \\
\hline 18 & Understands American military culture's cognitive biases & 2 & 2 & 2 & 2 \\
\hline 19 & $\begin{array}{l}\text { Basic knowledge of in-group and out-group dynamics (in-group } \\
\text { is any group the soldier belongs to like family or troupe while } \\
\text { out-group is any group of which he is not a member) }\end{array}$ & 3 & 2 & 2 & 3 \\
\hline 20 & $\begin{array}{l}\text { Understands self and how he or she relates to in-groups and out- } \\
\text { groups }\end{array}$ & 3 & 2 & 2 & 2 \\
\hline 21 & Ability to take perspective of in-group as well as out-group other & 2 & 2 & 2 & 2 \\
\hline 22 & $\begin{array}{l}\text { Knows the difference between an observation about another's } \\
\text { behavior and an interpretation of another's behavior }\end{array}$ & 1 & 3 & 2 & 1 \\
\hline 23 & Understands consequences of faulty perspective taking & 2 & 2 & 2 & 2 \\
\hline 24 & $\begin{array}{l}\text { Asks questions to check interpretation before making decisions } \\
\text { about next steps }\end{array}$ & 1 & 3 & 2 & 2 \\
\hline 25 & Tolerates uncertainty and postpones judgment & 2 & 2 & 2 & 2 \\
\hline 26 & Increases positive attitudes toward people of other cultures & 2 & 1 & 1 & 2 \\
\hline
\end{tabular}




\begin{tabular}{|c|c|c|c|c|c|}
\hline 27 & Increases openness to other cultures & 2 & 2 & 2 & 2 \\
\hline 28 & Understands the notion that one culture is not better than another & 3 & 3 & 3 & 2 \\
\hline 29 & $\begin{array}{l}\text { Understands that some judgments the soldier makes about host } \\
\text { nationals and vice versa have their basis in general cultural } \\
\text { differences }\end{array}$ & 2 & 2 & 2 & 2 \\
\hline 30 & $\begin{array}{l}\text { Understands that a behavior can be interpreted differently based } \\
\text { on culture }\end{array}$ & 2 & 2 & 2 & 2 \\
\hline 31 & $\begin{array}{l}\text { Understands the universal values, beliefs, and attitudes that all } \\
\text { cultures share }\end{array}$ & 2 & 1 & 1 & 1 \\
\hline 32 & $\begin{array}{l}\text { Understands concept of cultural cognitive biases and their } \\
\text { importance to effective perspective taking }\end{array}$ & 2 & 3 & 3 & 3 \\
\hline 33 & $\begin{array}{l}\text { Understands difference in thinking about men and women's roles } \\
\text { in different cultures }\end{array}$ & 2 & 1 & 1 & 1 \\
\hline 34 & Understands differences in thinking based on religion & 1 & 1 & 1 & 1 \\
\hline 35 & $\begin{array}{l}\text { Anticipates areas of potential conflict based on thinking } \\
\text { differences }\end{array}$ & 1 & 1 & 1 & 1 \\
\hline 36 & Alters behavior based on taking others' perspective & 2 & 2 & 2 & 2 \\
\hline 37 & $\begin{array}{l}\text { Knows pitfalls of stereotypes and prejudices towards people of } \\
\text { other cultures and how they can lead to faulty social perspective } \\
\text { taking }\end{array}$ & 2 & 2 & 3 & 2 \\
\hline 38 & $\begin{array}{l}\text { Understands other factors and biases that influence perceptions } \\
\text { of self and others (for instance, tendency for people involved in } \\
\text { a situation to view things differently from people not involved in } \\
\text { the situation): }\end{array}$ & 2 & 2 & 1 & 3 \\
\hline 39 & $\begin{array}{l}\text { Understands how host national may perceive the soldier based } \\
\text { on cultural differences and stereotypes }\end{array}$ & 1 & 2 & 1 & 2 \\
\hline 40 & Communicates empathy towards a person from another culture & 2 & 3 & 3 & 3 \\
\hline 41 & $\begin{array}{l}\text { Uses social mimicry (mimics things like dress, eating habits, } \\
\text { body language) skillfully to reinforce perspective taking } \\
\text { response to persons in another culture }\end{array}$ & 3 & 3 & 2 & 3 \\
\hline
\end{tabular}




\section{$\underline{\text { Soldiers’ Responses to Open-Ended Questions }}$}

Question 1: Of the aforementioned KSAs, which do you think is the most important for the Soldier to possess and why?

Subject $1 \quad$ \#35 - well informed anticipation can prevent a whole host of problems and aid you in many of the other areas (keeping control of self, expression, etc).

Subject 2 People observation and non-verbal communication. These are the basis for all else that follows.

Question 2: Of the aforementioned KSAs, which do you think is the least important for the Soldier to possess and why?

Subject $1 \quad$ \#28, too likely to devolve into some sort of PC "we are all equal" and allowing for tolerance of the truly abhorrent.

Subject 2 From a military perspective, the communication of empathy, and social mimicry. Empathy can hinder mission accomplishment, by getting a Soldier too close, emotionally, to a deadly situation, some aloofness must be maintained. Social mimicry has its place with Special Forces Operations but conventional troops are generally not allowed and are restricted in these areas.

Question 3: Are there any relevant KSAs missing?

Subject $1 \quad$ Not as long as each host nation is covered specifically.

Question 4: What advice or suggestions do you have for us in planning cross-cultural perspective taking curriculum? Any resources you think we should be aware of?

Subject 1 A mix of video, role play and computer simulation AFTER a lecture would help really cement the lessons well.

Subject $2 \quad$ Keep it simple. Plenty of troops will be resistant to the idea in the first place and if it's too big or too long or too involved they'll foreclose their attention. This could easily be a doctoral level course, resist that and keep it simply. Maintain a mission accomplishment orientation in the presentation. 


\section{Appendix D}

\section{Interview Methodology}

\section{SPT Academic Expert Interviews}

Our expert interviews consisted of six 1-hour interviews with experts.

These interviews influenced us as to which of the KSAs are most important for teaching cross-cultural perspective taking as well as the best methodology for teaching them. The expert interviewees were found through the literature and were all names that are often cited in either the cross-cultural literature or the SPT literature.

The interviews began by asking the experts what would be most crucial in teaching intercultural perspective taking and why. Interviewees were prompted with open ended questions that had them expound on their previous comments. The "what" as well as the "how" of teaching SPT were the main topics covered.

\section{Soldier Interviews}

Our Soldier interviews involved three carefully prepared rounds of interviews:

For Round 1 of the interviews, the authors prepared interview questions for classes of interviewees and supplemented them with questions tailored to individual cultures and people. The authors prepared interviewees by doing pre-interviews by email or phone in which they became acquainted with social perspective taking issues and were offered materials to help them prepare to tell stories based on personal experience. Based on these interviews a repository of stories dealing with SPT and/or cultural miscommunication themes was built.

For Round 2, the authors created follow-up questions to encourage interviewees to deepen their interviews with more detail, more anecdotes, and more information specifically related to cultural perspective taking. The case studies are heavily influenced by these stories and the cross-cultural case study is a composite of several Soldier stories.

For Round 3, one Soldier and 2 retired Soldiers gave feedback about our proposed perspective taking curriculum. Their feedback was incorporated in revision of the curriculum design. 
Appendix E

\section{Description of the Four Proposed Curriculum Modules}

The primary KSAs gleaned from the literature review and interviews for SPT can be organized into three key categories:

- KSAs related to understanding of and SPT related to the self

- KSAs related to understanding of and SPT related to a familiar other

- KSAs related to understanding of and SPT related to an unfamiliar, cross-cultural other

and are reflected in the following four proposed training modules:

- Introduction to Social Perspective Taking Module;

- Exploration of the Self Module;

- $\quad$ SPT with A Similar Other Module; and

- SPT with A Culturally Different Other Module.

The twenty-two KSAs are embedded throughout the four modules and through video cases, discussion, short expert "lectures", role plays, and scenario vignettes. The curriculum introduces each KSA and then spirals back to it throughout the training. Table E-1 shows where each KSA is first introduced. 
Table E-1

Where Each KSA is First Introduced in the Curriculum

\begin{tabular}{|l|l|}
\hline Primary Knowledge & \multicolumn{1}{|c|}{$\begin{array}{c}\text { Module Where KSA Is First } \\
\text { Introduced }\end{array}$} \\
\hline $\begin{array}{l}\text { Understand Social Perspective Taking concept and relevance to } \\
\text { successful intercultural communication and to mission success }\end{array}$ & Introduction \\
\hline Recognize fundamental attribution error & Self Exploration \\
\hline Recognize naïve realism & Self Exploration \\
\hline Recognize confirmation bias & Self Exploration \\
\hline Understand consequences of faulty perspective taking & Familiar Other \\
\hline Understand the impact of in-group/out-group bias & Culturally Different \\
\hline $\begin{array}{l}\text { Understand how one's ideas, values, thoughts, and identity are } \\
\text { influenced by multiple factors, including culture }\end{array}$ & Self Exploration \\
\hline Secondary Knowledge & \\
\hline Understand how culture influences perception & Self Exploration \\
\hline Understand the pitfalls of stereotyping & Familiar Other \\
\hline $\begin{array}{l}\text { Understand the notion of cultural relativism and that one culture } \\
\text { is not better than another }\end{array}$ & Culturally Different \\
\hline Primary Skills & \\
\hline $\begin{array}{l}\text { Regulate emotions before and during cross-cultural stressful } \\
\text { communication exchange }\end{array}$ & Self Exploration \\
\hline $\begin{array}{l}\text { Extract cultural and contextual data through: observing, } \\
\text { listening, questioning, \& interpreting nonverbal behavior }\end{array}$ & Familiar Other \\
\hline $\begin{array}{l}\text { Develop tolerance for uncertainty and the ability to postpone } \\
\text { judgment }\end{array}$ & Familiar Other \\
\hline Correct for biases & Familiar Other \\
\hline Develop multiple hypotheses (2-3) during SPT attempt & Familiar Other \\
\hline Check for accuracy of SPT hypotheses & Familiar Other \\
\hline Confirm/disconfirm hypotheses & Familiar Other \\
\hline Adapt behavior based on chosen hypothesis & Familiar Other \\
\hline Gather feedback on one's action & Familiar Other \\
\hline Use cultural knowledge to influence hypotheses & Culturally Different \\
\hline Primary Attitudes & Introduction \\
\hline $\begin{array}{l}\text { Have the motivation and persistence to engage in SPT activity: } \\
\text { 1) Develop the disposition to engage in SPT frequently } \\
\text { constions to persist in SPT under challenging }\end{array}$ & \\
\hline Secondary Attitudes & Culturally Different \\
\hline Be open to other cultures & \\
\hline
\end{tabular}

As the teaching modules progress, the curriculum shifts from a culturally familiar to culturally different perspective taking target. Soldiers learn the process for effective SPT is the same for all targets, but that additional KSAs are needed for cross-cultural SPT. The curriculum 
builds on itself as noted above and "loops back" to reinforce the learning of key skills as the modules unfold.

The curriculum also makes the trainee aware of ubiquitous biases that may lead to faulty SPT including the fundamental attribution bias (FAE), naïve realism, confirmation bias, and ingroup/out-group biases. These were chosen because they are so common and lead so strongly to faulty perspective taking (Ames 2004; Gehlbach \& Brinkworth, in press).

The curriculum uses the case study method to train the KSAs. A case study can achieve training better than a lecture or discrete exercises and activities because it puts the student in the position of identifying with the protagonist and other characters in a real life story.

The curriculum also utilizes extensive video throughout the training. Videos provide Soldiers with real-life information-extraction experiences in that they are exposed to multiple channels and cues that are both verbal and -- essential to cross-cultural communication -nonverbal. A description of the four modules is provided below.

\section{Module 1: Introduction to Social Perspective Taking}

This module introduces the concept of social perspective taking and its relevance to Soldiers personally and professionally which is essential to a Soldiers' achievement of SPT (Corno et al., 2002). A goal of this module is to increase propensity to engage in SPT behavior frequently (Gehlbach, 2004). This will be accomplished through many learning strategies, including video presentation of Soldiers describing: 1 ) how faulty perspective taking can have disastrous consequences, 2) how taking a host national's perspective can be crucial to mission success and may reduce casualties, 3 ) when to use SPT and when it is not appropriate (e.g., activities involving reflex response such as combat). The introduction also includes a pre-assessment, which is connected to an SPT-related video. The assessment is integrated seamlessly into responding to the video scenario.

\section{Module 2: Exploration of the Self}

This module develops a Soldier's self-knowledge, biases, and ability to regulate his or her emotions. Teaching self-knowledge allows a Soldier to understand how his or her ideas, values, thoughts, and identity are influenced by multiple factors, including culture. The curriculum will accomplish this through the use of video and exercises.

Other self-exploration within this module introduces the trainee to three key biases: fundamental attribution error, naïve realism, and confirmation bias. These concepts will be presented through a case-based video that requires viewers to engage in SPT hypotheses as they try to understand the characters' thoughts and feelings and work out solutions to the characters' problems (Gilbert \& Malone, 1995; Gehlbach \& Brinkworth, in press)

Learning healthy strategies for emotional self-regulation involves body, affect, and mind. Through simple biofeedback and stress reduction exercises, Soldiers can learn to be more aware of their personal triggers for tension and stress, can practice stress reduction techniques, and can 
calm their bodies and thoughts. This physiological self-regulation is followed by exercises to increase emotional self-awareness, including recognition, labeling, expression and control of emotions. Fear and anger are especially important, as negative emotions, including as a reaction to another person's emotions and have been correlated with emotional distress, aversive behavior, and anxiety (Eisenberg, Shea, Carlo \& Knight, 1991). In contrast, healthy emotional regulation has been correlated with feelings of empathic concern for others (Derryberry \& Rothbart, 1988).

Soldiers can productively use emotional reasoning in their SPT work - to empathize intelligently, to make decisions about courses of action, to avoid judgment errors and bias, and to understand people who are quite different from themselves. In other words, emotions are not just "feelings", rather, they are a form of perspective and they involve judgment (Derryberry \& Rothbart, 1988).

\section{Module 3: Perspective Taking with a Similar Other}

The curriculum will emphasize much of what was discovered in the literature review in regards to agency and empathy. Specifically the Soldier will be taught that they do not need to feel as the host national does; instead, they will be taught how to recognize how the other person feels and why, and how to communicate that knowledge while maintaining a sense of self. Although some SPT happens at the unconscious level, it is mainly an active process in which the perspective taker imagines similarities and differences between his experiences and those of another person.

Once Soldiers have performed self-exploration in the previous module, they will complete a module that will teach them SPT strategies based upon a video case involving Similar Others. According to studies by Mendoza (1997) and Galinsky and Moskowitz (2000), as students learn to implement SPT strategies, their SPT accuracy will increase. The curriculum will introduce strategies through the innovative, research-based four-step SPT process for accurate perspective taking. The four-step SPT method is introduced, demonstrated, and practiced in this module through a video case study.

\section{Module 4: Perspective Taking with a Cross-Cultural, Very Different Other}

Most of the introductory SPT training is in the cross-cultural module. It introduces crosscultural issues and uses a new video case, role play, and scenario vignettes to apply the four-step method within cross-cultural contexts. Role plays will be developed for schoolhouse instruction and scenario vignettes will be developed for stand-alone instruction.

This module provides the trainee with practice of the four-step method in a range of crosscultural contexts. In particular, the training will concentrate on biases related to group membership which have been shown to be extremely common causes of cross-cultural misunderstanding and faulty SPT hypotheses (Devine, 1995; Brewer, 1979; Rosenbaum \& Holtz, 1985). An example of how to apply the four step process in a cross-cultural context follows. 
When Soldiers apply Step 1 - You don't know what you don't know - they are prodded to think about what they know about the other's culture and how that information is affecting their initial hypothesis and the other's situation. Once Soldiers consider cultural issues in this context, they can take steps to get more information from: the other party, an interpreter, and their peers. Also, SPT typically happens quickly - often too quickly. Soldier interviews have illustrated that decisions in-theater are often the result of either a real or perceived operational urgency. It is extremely helpful to illustrate to Soldiers that deliberation, when appropriate, improves SPT accuracy.

In Steps 2 and 3 - "Consider self, then other" and "Check-in", Soldiers learn to select/categorize information (Jandt, 2001). This is important, as they can check to see whether they are disregarding possibly important information or failing to consider cultural cognitive biases or other cultural differences. Trainees can also note how they are organizing information and whether American cultural perspectives are being imposed upon their assumptions. Thus, hypothesis generation and clarification will consider cultural information.

In step 4 - "Invest in Outcome" -- Soldiers verify meaning of their hypotheses where possible and adapt accordingly. An excellent technique for this is "back translation" where they reflect back to the other party what the party has said (Jandt, 2001). Translation can occur with or without the use of an interpreter; if an interpreter is needed the interpreter will translate the Soldier's speech into the host nation language and then translate the host national's speech back into English. If an interpreter is not needed then the Soldier can restate his assumption directly in a shared language followed by the host national's confirmation of those assumptions.

In addition to role-plays in the classroom, Soldiers explore computer scenarios in the stand-alone instruction with branching exercises, immediate feedback, looping for review and remediation, and summative evaluation. If computers are available, Soldiers can also have access to the branching scenarios. Soldiers can redo SPT method steps that they have difficulty with and work on multiple hypothesis generation and verification. They will be expected to ask questions and display culturally sensitive listening and interpretation skills, and to invite the interlocutor to share additional information, and to confirm information. An assessment strategy for determining the effectiveness of the training can be found in Appendix F. 
Appendix F

\section{An Assessment Strategy}

The goal of the curriculum is to develop Soldiers' KSAs related to SPT. Specifically, as Soldiers advance through the course, they should:

- become more knowledgeable about basic biases and the process of SPT

- increase propensity to engage in SPT, regulate emotions, and persist in SPT attempts

- improve SPT accuracy and be more skilled at developing/evaluating multiple hypotheses.

The success of the curriculum as a whole depends upon whether individual Soldiers demonstrate improvement in these three areas. To confidently infer that the curriculum has caused these improvements, a pre-post design is insufficient. eCrossCulture thus proposes a true experiment as the evaluation methodology. However, a classic experiment has several drawbacks. First, leaving selected Soldiers untrained in SPT undermines the Army's efficacy. Second, with a short intervention, one needs to be able to assess how long the intervention's effects last. Third, if Soldiers do not keep up with the course, one needs a way to find out and remediate the situation.

To address these issues, this project proposes a true experiment with a lagged control group design, formative assessments, and follow-up assessments. This design requires Soldiers to be randomly assigned to groups prior to the initial implementation of the curriculum. For the first round, both a training and a control group are selected. Both are assessed initially and again after the training group has completed the curriculum. Differences in post scores and in gain scores are calculated to determine between-group differences. For round two, the control group of round one becomes the experimental (training) group. The groups are then compared to a newly selected group that serves as the new control group. The design allows us to assess the longevity of the curriculum's effects by re-assessing the initial training group once the second training group has completed the curriculum. Table 3 shows the assessment timeline.

Table F-1

Assessment Timeline and Group Composition

\begin{tabular}{|l|l|l|l|l|l|l|l|l|}
\hline Group & $\begin{array}{l}\text { Pre-impl. } \\
1\end{array}$ & $\begin{array}{l}\text { Post } \\
\text { impl. 1 }\end{array}$ & $\begin{array}{l}\text { Pre-impl. } \\
2\end{array}$ & $\begin{array}{l}\text { Post } \\
\text { impl. 2 }\end{array}$ & $\begin{array}{l}\text { Pre-impl. } \\
3\end{array}$ & $\begin{array}{l}\text { Post } \\
\text { impl. 3 }\end{array}$ & $\begin{array}{l}\text { Pre-impl. } \\
4\end{array}$ & $\begin{array}{l}\text { Post impl. } \\
4\end{array}$ \\
\hline 1 & Expmtl. & Expmtl. & & $\begin{array}{l}\text { Follow } \\
\text { up } \\
1\end{array}$ & & $\begin{array}{l}\text { Follow } \\
\text { up 2 }\end{array}$ & & $\begin{array}{l}\text { Follow } \\
\text { up 3 }\end{array}$ \\
\hline 2 & Control & Control & Expmtl. & Expmtl. & & $\begin{array}{l}\text { Follow } \\
\text { up 1 }\end{array}$ & & $\begin{array}{l}\text { Follow } \\
\text { up 2 }\end{array}$ \\
\hline 3 & & & Control & Control & Expmtl. & Expmtl. & $\begin{array}{l}\text { Follow } \\
\text { up 1 }\end{array}$ \\
\hline 4 & & & & & Control & Control & Expmtl. & Expmtl. \\
\hline
\end{tabular}


To know whether individual Soldiers are keeping up, multiple formative assessments have been embedded within the curriculum itself. Because cases and assessments are curricular activities, assessments feel seamless to Soldiers. This makes possible measurement of which Soldiers are mastering the course content. A limitation of standard formal assessments measurement error - is introduced when some students become nervous and others rise to the occasion (compared to how they would normally perform in the real world). The formative assessments provide regular, consistent feedback that will allow us to proactively identify and remediate difficulties individual Soldiers are having. In addition, they will provide more ecologically valid data.

eCrossCulture (eCC) proposes a rigorous validation methodology; it has been developed without collaboration with ARI. The Army's operational needs may require modifications to the approach. Modifications will be made as desired by the Army and eCrossCulture will obtain approval from the COR before commencing activity.

\section{Data to be Collected}

The main assessment measures will evaluate Soldiers':

- Knowledge about their own biases and the biases of others.

- Attitudes about engaging in SPT regularly, extracting more information from perspective taking targets, and generating multiple hypotheses.

- Skills at the four-step SPT process, mitigating their own biases, choosing and revising hypotheses supported by the best evidence, and evaluating their chosen action.

Three components of Soldiers' attitude about engaging in SPT regularly will be assessed through an SPT survey. Dr. Gehlbach has begun a validation study of this measure that will be ready in time for the pilot testing of the curriculum and its assessment battery. The evaluation will also adapt Cacioppo and Petty's (1982) 'need for cognition' measure to assess Soldiers' attitudes about seeking more information from their perspective taking targets. To avoid relying on Soldier self-report data, the evaluation protocol will also ask Soldiers' commanding officers to provide feedback.

To assess their SPT skill, Soldiers will complete performance tasks. These tasks require Soldiers to discern the thoughts and feelings of two people interacting in a video clip. These video clips, which already exist, are undergoing a validation study that will be completed by the time of pilot testing the full curriculum and assessment battery.

To assess knowledge about biases, eCC will test soldiers on defining the taught biases and demonstrating their ability to identify them in different written and video scenarios. Recognizing when different biases are likely to emerge in real life contexts is the more critical skill. Thus, the assessment will be heavily weighted towards measuring that knowledge.

Soldiers' attitudes about the specific KSAs mentioned above will be assessed through a series of interactive, scenario-based, multi-media exercises. Soldiers in the experimental and control groups will complete a branching exercise that presents different scenarios Army 
personnel have actually encountered in the field. Through the existing interview repository, eCC has a base from which to develop these stories. Through written descriptions and video-taped interviews, sections of scenarios will be played. Periodically, scenarios will be stopped and Soldiers asked to decide on next steps and actions. Soldiers will experience this as an engaging "choose your own adventure" while data is collected on the following:

1) the number of different hypotheses they entertain, 2) what evidence they marshal in support of each hypothesis, 3) how they evaluate that evidence, 4) what action they choose, and 5) their perspective on why they chose a particular course of action

\section{Instrument Development}

All instruments will be developed during the first year including: the attitude about engaging in SPT; the SPT skill assessment; the adaptation of Cacioppo and Petty's (1982) need for cognition; the scenario-based knowledge assessment of biases and scenario-based multimedia assessment of Soldiers' attitudes/skills in generating, evaluating, and taking action on multiple hypotheses.

To develop assessments of Soldiers' knowledge of biases, the robust library of cross-cultural misunderstanding scenarios will be used. eCC will select ones that illustrate different biases. They will be developed into test items requiring Soldiers to identify which bias or biases are occurring and what the likely outcome will be. To obtain additional test items through video, we will interview the actual Soldiers who related these scenarios. These two approaches will allow us to assess Soldiers' abilities to detect bias both from written descriptions as well as from the richer medium of video. After developing several of these situations during Quarter 1 Year 1 of the Phase II effort, they will be pilot tested them during Quarter 2. The process will ensure that the final assessment has a range of difficulty of items and will allow us to assess improvement over time.

Development of the assessments of Soldiers' attitudes and skills for generating, evaluating, and taking action on multiple hypotheses will require a more involved process. First, Soldiers will be interviewed and videotaped to collect a number of brief scenarios that can be used for these scenario-based, multimedia assessments. The materials will be broken down into 4-5 decision points or branches that offer a Soldier various possible paths to pursue. Supporting documents and additional evidence will enable Soldiers to make informed decisions.

\section{Data Collection Procedure}

Soldiers who are participating in both the training groups and the control group will complete the full battery of these seven major assessments before either training group begins the curriculum. After completing the curriculum, both the training groups and the control group will again complete all seven major assessments. Because of the short time interval, there is a need to create multiple assessment instruments for the skill assessments. Otherwise one runs the risk of testing memory rather than skill improvements. 
Assessment of skill at SPT will require different performance tasks to be administered pre and post. Through pre-testing, eCC will insure that performance tasks are of equal difficulty. A counterbalanced design such that half of training group 1, training group 2, and the control group get video $\mathrm{A}$ at pre and video $\mathrm{B}$ at post is proposed. The other half of each group gets video $\mathrm{B}$ at pre and video A at post. Similarly, follow-up assessments similarly need to be different performance tasks. The scenario-based multi-media assessments that measure skills and attitudes related to generating and choosing best hypotheses and evaluating chosen actions will also need to be different for pre and post and will have to be counterbalanced in their administration. In addition to these pre and post assessments, Soldiers in the two training groups receive multiple formative assessments throughout the course as part of the case learning experience. These assessments will monitor Soldiers' progress in their development of key KSAs and provide go/no go cut points to indicate whether Soldiers need to review certain material or not. 